\title{
LA-4780 (ENDF-174)
}

A Preliminary Evaluation of the Neutron and Photon-Production Cross Sections of Oxygen

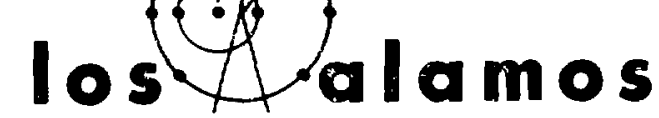

scientific laboratory

of the University of California

LOS ALAMOS, NEW MEXICO 87544

$\downarrow$ 
This report was prepared as an account of work sponsored by the Unized States Government. Neither the United States nor the United States Atomic Energy Commission, nor any of their employees, nor any of their contractors, subcontractors, or their employees, makes any warranty, express or implied, or assumes any legal liability or responsibility for the accuracy, completeness or usefulness of any information, apparatus, product or process disclosed, or represents that its use would not infringe privately owned rights.

Printed in the United States of America. Available from National Technical Information Service

U. S. Department of Commerce 5285 Port Royal Road

Springfield, Virginia 22151

Price: Printed Copy $\$ 3.00$; Microfiche $\$ 0.95$ 


\section{A Preliminary Evaluation of the Neutron and Photon-Production Cross Sections of Oxygen}

by

D. G. Foster, Jr.

P. G. Young 
ABSTRACT

1. TNTRODUCTION 1

2. NEUTRON AND PHCTON-PRODUCTION CROSS SECTIONS 2

2.1 Total Cross Section

2.2 Radiative Capture Cross Section 6

2.3 Inelastic Scattering Cross Sections 6

2.3.1 The $16_{0}\left(n, n^{\prime}\right)$ and $1 \epsilon_{O}\left(n, n^{\prime} \gamma\right)$ Cross Sections for
$E_{x}\left(16_{0}\right)<13 \mathrm{MeV}$

2.3.2 The $160\left(n, n^{3}\right)$ Cross Section for $E_{x}\left({ }^{16} 0\right)>13 \mathrm{MeV} \quad 13$

2.4 The $16_{O}(n, p)^{16} \mathrm{~N}$ and ${ }^{16} \mathrm{O}(\mathrm{n}, \mathrm{p \gamma})^{16_{\mathrm{N}} \text { Cross Sections }} 13$

2.5 The $160(n, d) 15$ Cross Section 15

2.6 The $160(n, \alpha)^{13} \mathrm{C}$ and $\left.160(n, \infty)^{\circ}\right)^{13} \mathrm{C}$ Cross sections 15

2.7 Elastlc Scattering Cross Section 21

3. ANGULAR DISTRIBUTIONS 22

3.1 Elastic Neutron Angular Distributions 22

3.2 Inelastic Neutron Anguiar Distributions 24

3.3 Secondary-Photon Angular Distributions . . 25

4. DISCUSSION 25

5. ACKNONLEDGMENTS 27

REFERENCES 


\title{
A PRELTMINARY EVALUATION OF THE NEUTRON AND
}

PHOTON-PRODUCTION CROSS STCTIONS OF OXYGEN

by

D. G. Foster, Jr., and P. G. Young

ABSTRACT

\begin{abstract}
A preliminery evaluation of the neutron-induced crosis sections of $16_{0}$ has jeen completed for the energy region $10^{-5} \mathrm{eV}$ to $20 \mathrm{MeV}$. Energy and angular distributions of secondary neutrons and photons are included. The recomended data are based mainly on experiment, although model calculations were used to augment the measurements in certain areas. In addition, results from an earlier evaluation performed at the Knolls Atomic Power Laboratory are also Included to a limited extent. The evaluated data are available on magnetic ta $:$ in ENDF/B(III) format.
\end{abstract}

\section{TNTRODUCTION}

A preliminary evaluation of the neutron and photon-production cross sections of oxygen has been completed for the energy range $10^{-5} \mathrm{ev}$ to $20 \mathrm{MeV}$. Except in the region of the "window" at $2.35 \mathrm{MeV}$, natural oxygen is treated entirely as ${ }^{16} O$, and the $0.23 \%$ of ${ }^{17} 0$ and ${ }^{18} O$ is ignored. The data are in ENDF/B (III) format as MAT $11 ; 34$ and heve been provided to the Radiation Shielding Information Center at Cak Ridge and to the National Neutron Cross Section Center at Brookhaven.

The primary purpose of this work is to provide the Defense Nuclear Hgency with an interim set of cross-section data which contains a consistent set of evaluated inelastic-neutron and photon-F.roduction cross sections and which Includes consideration of several important new measurements. A complete Itterature survey was not perfoumed for this study, although many new measurements are included. Parts of the 1965 evaluation by Slaggie end Reynolds (SI65) at the Knolls Atomic Power Iaboratory (KAPL) have been incorporcted in the evaluation. The present stidy is incomolete in several areas and should be regarded as preliminary.
A simvey of th: reactions of interest is given schematically in Fig. 1 (Aj59, Aj70, Aj71). The $(n, y)$ reaction has been omitted from Fig. $I$ because it is very small above the electron-volt region and can be neglected for most; purposes. The $Q$-values and trresholds for various $n+{ }^{16} 0$ reactions are given in Table $I$.

The only significaut channel below the $\left(n, \alpha_{0}\right)$ threshold at $2.354 \mathrm{MeV}$ is elastic scattering, and in practice the Coulomb barrier inhibits the $\left(n, \alpha_{0}\right)$ reaction up to alinost $4 \mathrm{MeV}$. Similarly, the 3.09MeV photon from the $\left(n, \alpha_{1}\right)$ reaction to the first excited state of ${ }^{13} \mathrm{C}$ dues not become detectable until aoove $7 \mathrm{NeV}$, although its threshold occurs at $5.64 \mathrm{MeV}$. Above $7 \mathrm{MeV}$, inelastic scattering is the dominant reaction chennel. Although the $\left(n, n^{\prime} \alpha\right)$ channel opens at $7.61 \mathrm{MeV}$, parity ennservation inhibits the levels in ${ }^{16} \mathrm{o}$ below $9 \mathrm{MeV}$ excitation from decaying by alphe emission, and the $\left(n, n^{\prime} \alpha\right)$ reaction does not become significant until above 11. MeV. At energies above $12.89 \mathrm{MeV}$, proton emission from excited states in ${ }^{16} 0$ competes with alpha emission; however, at all energies the ( $\left.n, n^{\prime} p\right)$ reaction remains less important than the $\left(n, n^{\prime} \alpha\right)$ reaction. In this study the $\left(n, n^{\prime} p\right)$ and $\left(n, n^{\prime} \alpha\right)$ 

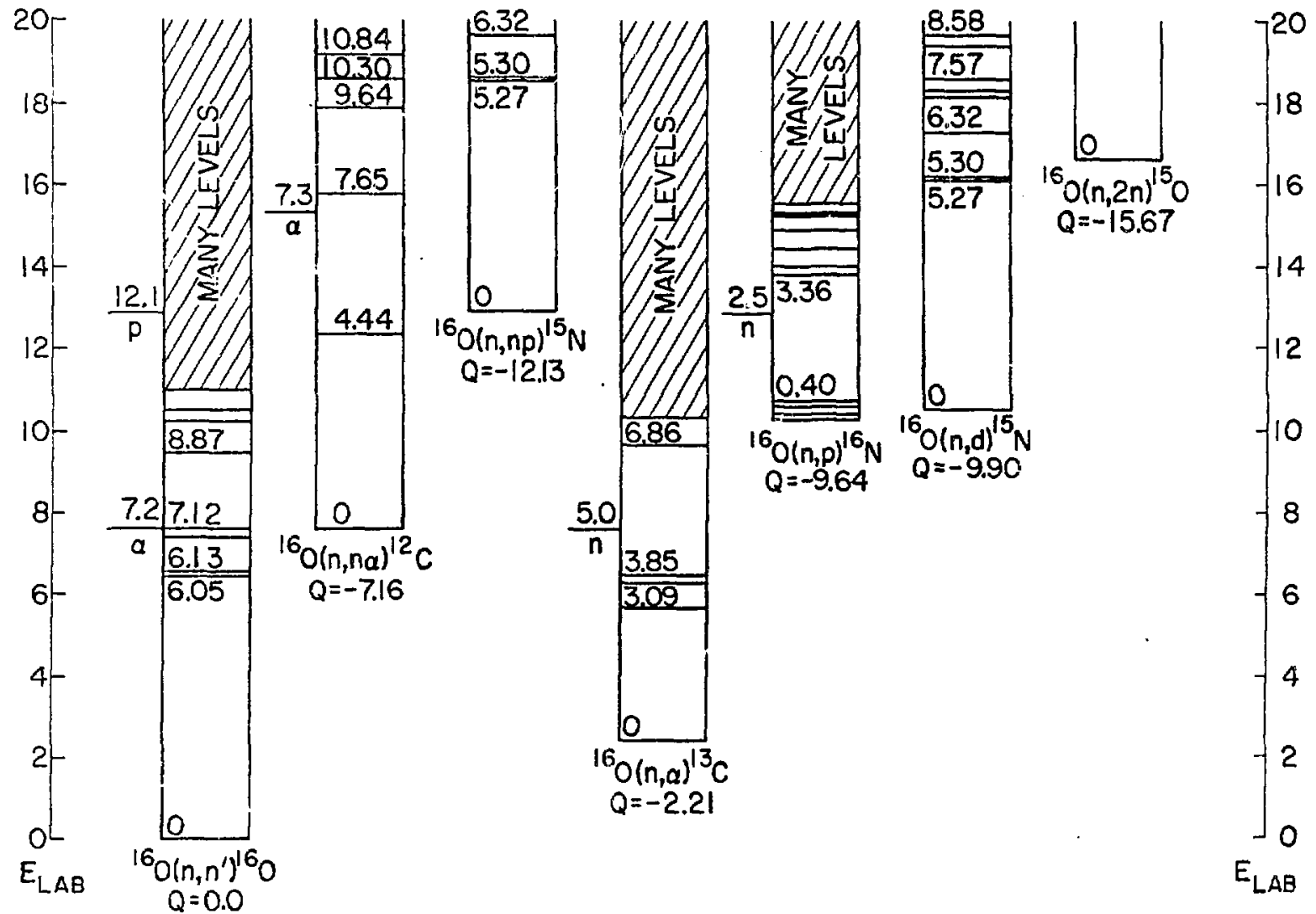

F1g. 1. Composite energy-level diagram for the residual nuclel of major interest formed in il +160 reactions. Except for the " $\mathrm{E}_{\mathrm{lab}}$ " scales, the energies are in the center-of-mass system, and all energies are
given in MeV.

relictions are included in the discrete $\left(n, n^{\prime}\right)$ ENDF/B files, with apjoropriate flags to indicate particle emission from the residual ${ }^{16} 0$ excited states.

The threshold for the $(n, p)$ reaction occurs at $10.25 \mathrm{MeV}$, followed closely by the $(n, d)$ threshold at $10.53 \mathrm{MeV}$. The latter reaction is relatively unimportant, ns its cross section is less than $16 \mathrm{rab}$ at all energies The cross section for the ( $n .2 n$ ) reaction is less than $3 \mathrm{mb}$ below $20 \mathrm{MeV}$ $(\mathrm{Br} 6 \mathrm{I})$, and it is not included in the evaluation. Simflarly, the $(n, t),\left(n,{ }^{3} H e\right)$, and $(n, 2 \alpha)$ reactions Isted in Table I are expected to have very small cross sections and have been ignored.

The neutron total cross section was obtained at all energies from experimental data. Below $11 \mathrm{MeV}$, the elestic cross section was determined by subtrecting the sum of all reaction cross sections, which sere deteminer? maini.y from measurements, from the eveluated totai cross section. Betiveen $l l$ and
$14 \mathrm{MeV}$, increasing emphas is was placed on the measured elastic cross section, and above $14 \mathrm{MeV}$ the nonelastic cross section was determined by subtraction of the elastic from the total. The no.selastic cross section was extended to $20 \mathrm{MeV}$ by optical model calculations. ibove $14 \mathrm{MeV}$ the $(n, p)$, $(n, d)$, and $(n, \alpha)$ cross sections were teken from measurements, and the $\left(n, n^{\prime}\right)$ cross section to $h i$; $h l y$ excited states of ${ }^{16} 0$ was adjusted to give the correct nonelastic cross section.

\section{NEUTRON AND PHOTON-PRODUCTION CROSS SECTIONS}

\subsection{Totel Cross section}

The total cross section has been completely re-evaluated. Because our main purpose was to incorporate recent measurements, we gave less attention to the older work, especially in the millionelectron-volt region. Below $700 \mathrm{kev}$, however, the evaluated tota? cross section is based entirely on 
TABLE I

Q-VALUE ${ }^{\mathrm{a}}$ AND THRESHOLD FOR SEVERAL $n^{+16} 0$ INTERACTIONS

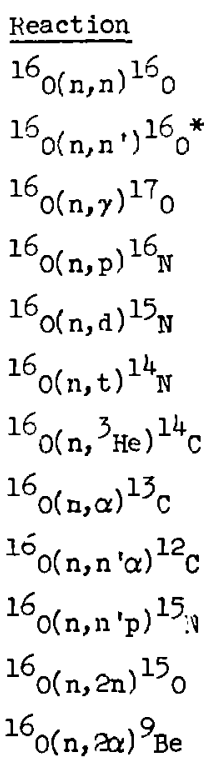

Threshold (MeV)

0

5.432

0

10.247

10.526

15.392

15.538

2.354

16.656

13.676

$\bar{a}$ All Q-values used in this evaluation are taken from the 1964 mass tables of Mattach et al. (Ma65).

very old measuremen's. From a preliminary approximate fit to the data of okazak1 (0k55), the first resonance was found to have $\mathrm{E}_{r}=442 \mathrm{keV}$, $\sigma_{0}=13.03 \mathrm{~b}$, and $\Gamma=48 \mathrm{kev}$, all in the laborator system. By subtracting the tail. of the resonence from three measurements below $250 \mathrm{keV}$ (Ad49, Jo48, Mel9), we obtained a weighted average of 3.6661 $0.015 \mathrm{~b}$ for the low-energy poten'ial-scattering cross section. If the $(n, y)$ cross section is assumed to vary as $1 / v$ from Jurney's value (Ju71) of $178 \mathrm{hb}$ at $2200 \mathrm{~m} / \mathrm{sec}$, 1t contributes an additionel $9 \mathrm{mb}$ to the total cross section at $10^{-5} \mathrm{ev}$, but is negligible above the electron-volt region. The potential-scattering background was assumed to vary linearly in the neighborhood of the 442-keV resonance in such a manner that the total cross section joins smoothly at $700 \mathrm{kev}$ onto the curve deduced at higher energies. The result is shown in Figs. 2 and 3, together with the data. Near $300 \mathrm{keV}$ the total cross section is a fes percent higher than the KAPL evaluation.

The remainder of the evaluated total cross section is based primarlly on three major time-ofplight, measurements which have become avallable since the 1965 evaluation. The measurement of Foster and Glasgow (Fo71) had the poorest resolution and the least reliable energy scale (especially below $3.5 \mathrm{MeV}$ ), but was part of an extensive series of systematic measurements which allows additional comparisons to be made with other work on other elements. It agrees with the results of Schwartz (Sc71) within about $0.5 \%$, on the average, in the overlap interval of 2.25 to $15 \mathrm{MeV}$. Since the two measurements use different samples $\left(\mathrm{B}_{2} \mathrm{O}_{3}-2 \mathrm{~B}\right.$ and $\mathrm{SiO}_{2}-\mathrm{Si}$, respectively), and similarly goor agreement has been observed previously in nitrogen (Yo72) and aluminum ( $Y \circ 72 a$ ), the Foster and Glasgow and the Schwartz measurements were adopted as standards for the million-electron-volt region.

The measurement by Clerjacks et al. (c168), who used $\mathrm{Al}_{2} \mathrm{O}_{3}$ with an aluminum blank, is the only one of the original 1968 group of Karlsruhe measurements that has not subsequently been assigr ad a recorrection for dead-time errors, and it is beileved to be correct withiı about $20 \mathrm{mb}$ at all energies above $700 \mathrm{keV}$ ( $\mathrm{Ci} 71$ ). However, the Cierjacks data disagree with other time-of-flight measurements in much the same say as Young and Foster (Yo72a) observed for aluminum (after recorrection), namely, there is a smooth variation ranging between $1 \%$ lower and $4 \%$ higher than the Foster and Glasgow (Fo71) and Schwartz (Sc71) results. Agreement is withij $1^{5}$ at almost ajl energies when a correction similar to that used for aluminum (Yo72a) is applied.

The evaluated cross section from 0.7 to $32 \mathrm{MEV}$ was taken directly from Schwartz's work (Sc71). However, since the Karlsruhe results had the best resolution of the three time-of-f'light measurements, we used inserts of those results, normalised by the correction discussed sbove, wherever necessery to preserve the resolution. Between 12 and $20 \mathrm{MeV}$ we used a composite of the work of Schwartz and Clerjacks. Below $4 \mathrm{MeV}$, the extremely narrow resonances found in the work of Fowler and Johnson (5070, Jo67) were corrected for resolution and superimposed on the base provided by the time-of-flight work. Unfortunately, we overlooked the fact that the earlier work of Fossan et al. (Fo61), which was the primary basis for the 1965 evaluation above $4 \mathrm{MeV}$, had 


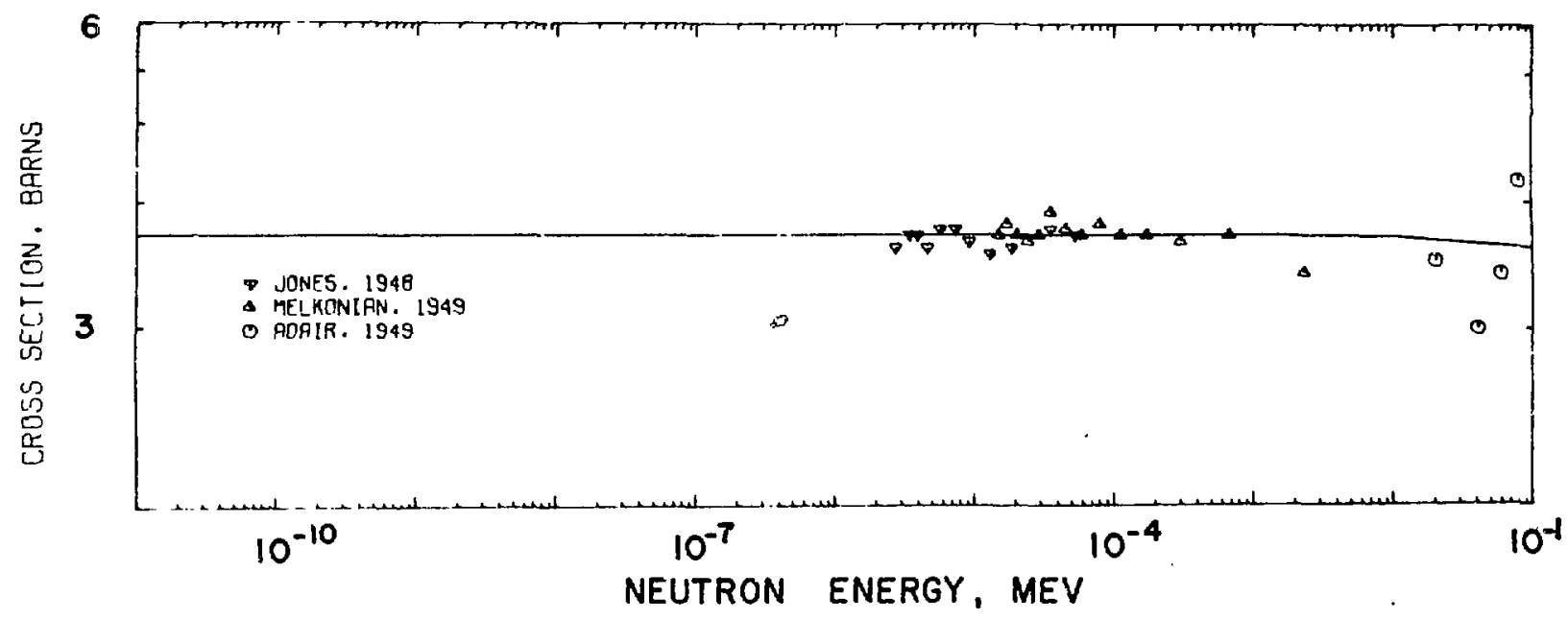

Fig. 2. Neasured and evaluated total. cross section for ${ }^{16} \mathrm{O}$ below $0.1 \mathrm{MeV}$.

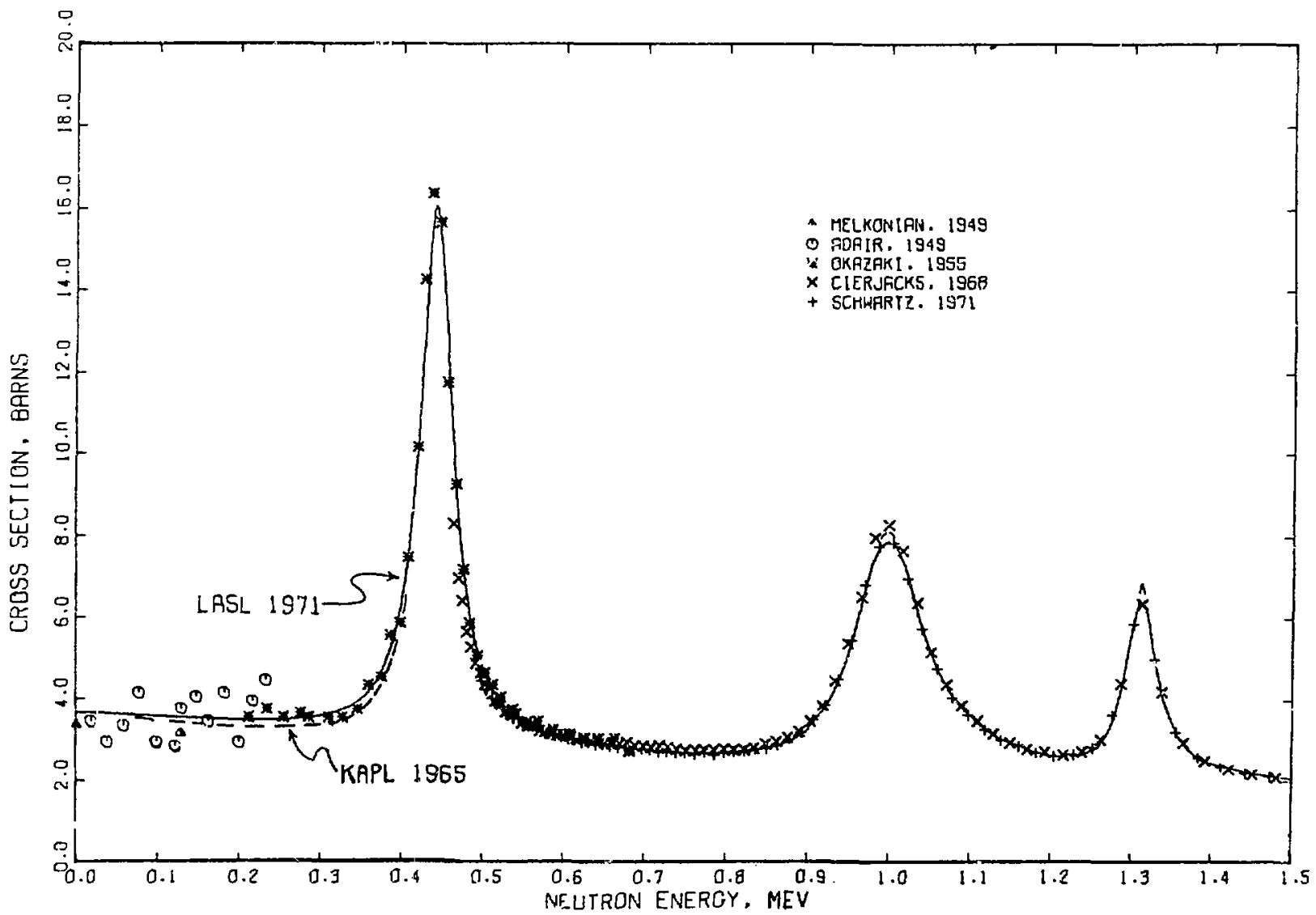

Fig. 3. Heasured and evaluated total cross section for ${ }^{16} 0$ from 0.01 to 1.5 MeV. The experimental points shoin are averages of 35 points for the Cierjacks data (C168) and 25 points for the Schwartz data (je?l). 


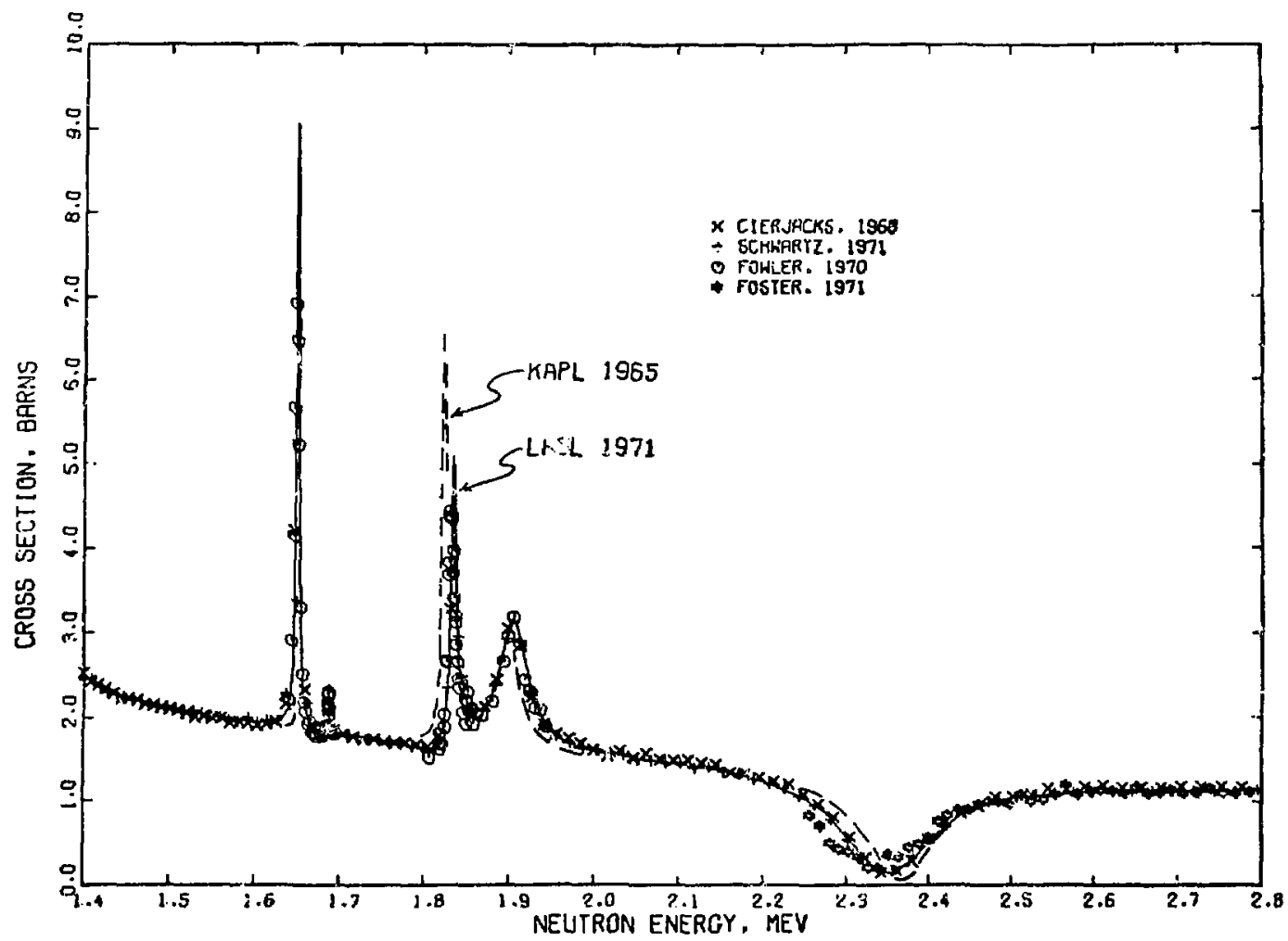

Fig. 4. Measured and evaluated total cross section for 0 from 1.4 to $2.8 \mathrm{MeV}$. The experimental points shown are averages of 11 points for the Clerjacks data (Ció) and 8 points for the Schwartz data $(\mathrm{Sc} 71)$.

better resolution* at some energies than the work of Clerjacks, although it liffers t'rom the recent time-of-flight measurements in absolute cross section, especially at higher energles. Therefore, although the present evaluation should be more accurate in energy and absolute cross section, in isolated areas above $4 \mathrm{MeV}$ its resolution is inferior to the 1965 evaluation.

Figure 4 shows the measured and evaluated cross section between 1.4 and $2.8 \mathrm{MeV}$, including the "window" in the total cross section near 2.35 $\mathrm{MeV}$. An energy shift between the older and more recent work is clee $21 \mathrm{y}$ visible at the $1.83 \mathrm{MeV}$ rescnance, For the window itself, two additional measurements were considered. After we applied corrections for resolution ranging from $80 \mathrm{mb}$ (Fo71)

*Note that in Figs. 3-7 the data of Cierjacks and Schuartz are plotted as averages of many adjacent points. This expedient introduces a further degradation of resolution in the figures but not in the evaluation. to neglifible ( $\mathrm{Ci68}$ ), we found that a value of $130 \pm 10 \mathrm{mb}$ for the minimum cross section of natural oxygen agreed with the three time-of-flight measurements and Fowier's (Fo7la) point-by-point work.* Four different sampies had been used for the four measurements (Fowler et al. used $\mathrm{BeO}-\mathrm{Be}$ ). We rejected, for the present, a preilminary result of $65+75 \mathrm{mb}$ made by Kelyma et al. (Ka71), who used a 5-ft-long sample of liquid oxygen. Later values reported by this group are higher and should be incorporated in the next evaluation. The present evaluation gives a window which is broader and shalIower than that of the 1965 evaluation and which appears at a slightily lower energy (Fig. 4).

\footnotetext{
* Final corrections were not made until after we completea the evaluation; the total crose section at the minimum in the EVDF/3 (III) data set is $139 \mathrm{mb}$.
} 
Figures 5-7 show the eveluated total cross secion in the energy range from 2.6-20 MeV, together with the datg used for the present evaluation and the measurement of Fossan et al. (Fo61), which was rot used. The loss of resolution can be seen at several energies. At about $8 \mathrm{MeV}$, the never measurenents and the present evaluation sho: a steady rise over the Fossail data and the 1965 evaluation. Near $14 \mathrm{MeV}$ there is a $12 \%$ difference which has an appreciable effect on air-transport calculations for 14-MeV neutrons. In addition, some of the proportionately larger changes in the elastic cross section discussed in Sec. 2.7 are due to subtraction from this nigher total cross section.

\subsection{Radiative Capture Cross Sention}

For the ${ }^{16} \mathrm{o}(\mathrm{n}, \mathrm{y})^{17} \mathrm{O}$ cross section for thermal neutrons, we used the Jurney and Motz (Ju63) value of $232 \mathrm{ub}$. The cross section at all other neutron energles was assumed to vary as $1 / y$ from the thermal value. This assumption results in $a n(n, y)$ cross section that is too small in the region of the inverse photonuclear giant resonance. However, the actual cross section in the million-electron-volt region is undoubtediy too low to be of interest in Tost practical problems.

The capture gamma-ray spectrum for thermal neutrons was obtained froril the measurements of Jurney (JuTI) and is given schematically in Flg. 8 . The total muitiplicity for thermal neutrons is 2.854 photons per captire.

2.3. Inelastic scattering Cross sections

$$
\begin{aligned}
& \text { 2.3.1. The }{ }^{16} O\left(n, n^{\prime}\right) \text { and }{ }^{16} O\left(n, n^{\prime} \gamma\right) \text { cross } \\
& \text { Sections for } E_{x}\left({ }^{16} 0\right)<13 \mathrm{MeV} \text {. The }
\end{aligned}
$$

$\left(n, n^{\prime}\right)$ cross sections to the most important photonproducing levels in ${ }^{16} 0$ were determined malnly from $\left(y, n^{\prime} y\right)$ measurements. The level decay scheme for ${ }^{16} 0$ which relates the $\left(n, n^{\prime}\right)$ and $\left(n, n^{\prime} \gamma\right)$ cross sections was obtained from the compllations of AjzenbergSelove (AJ59, AJ7O) and is given in Fig. 9. The photon transitions included in the evaluation are given in Table II.

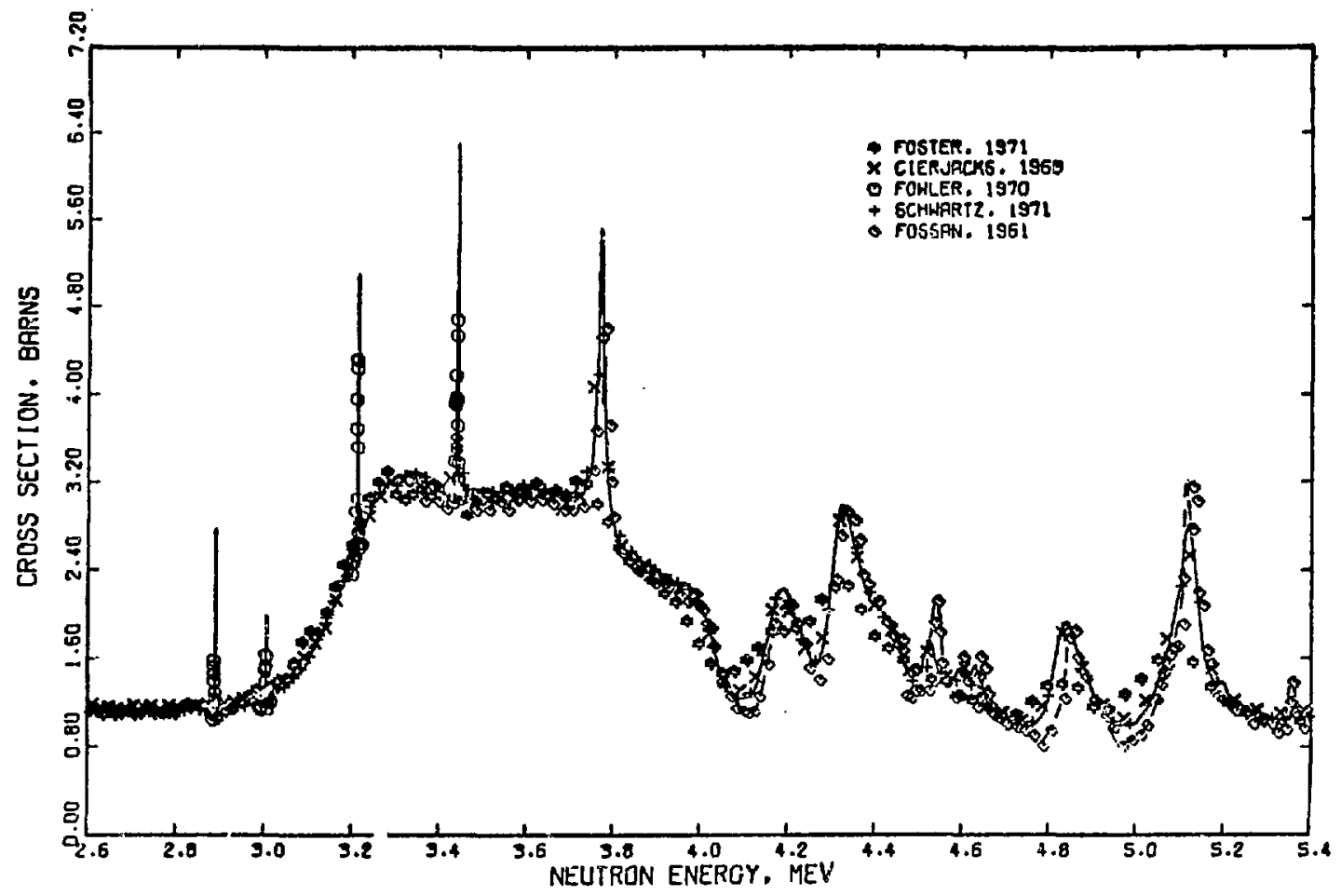

Fig. 5. Heasured and evaluated total cross section for ${ }^{16}$ o from 2.6 to 5.4 Mev. The experimental points shorn are averages of 9 points for the Cierjacks data (c168) and 5 points for the Schwartz data $(\mathrm{Sc} ? \mathrm{l})$. 


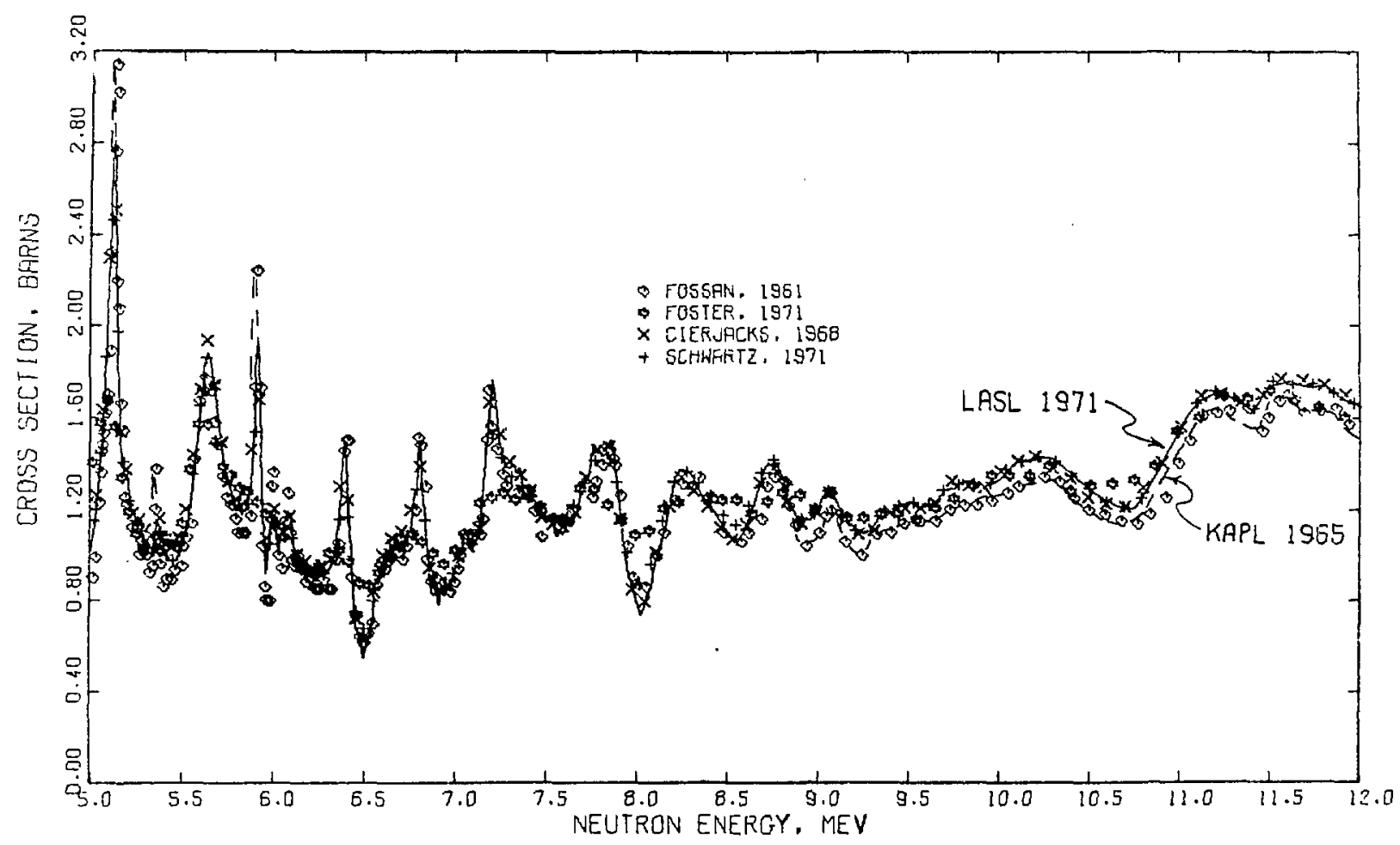

Fjg. 6. Measured and evaluated total cross section for 160 from 5.0 to 12.0 MeV. The experimental points shown are averages of 6 points for the Clerjacks data (C168) and 4 points for the Schwartz data (Sc71).

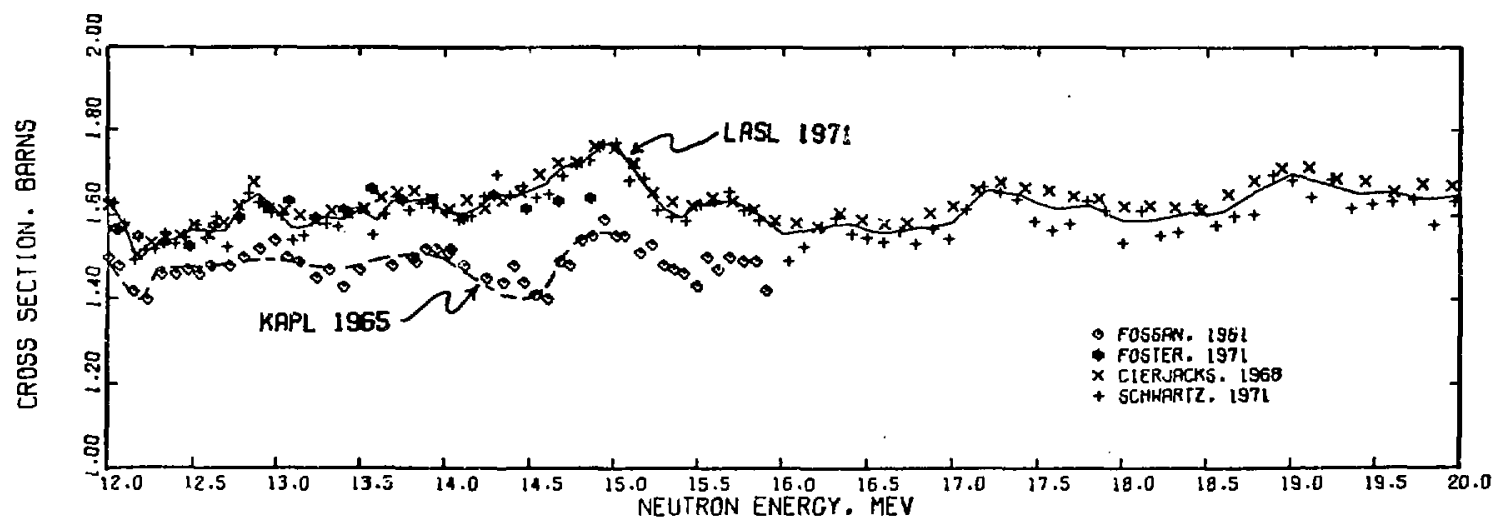

Fig. 7. Measured and evaluated total cross section for 160 from 12.0 to 20.0 MeV. The experimental points shoin are averages of 4 polnts for the Cierjacks date (Ci68) and 2 points for the Sehwartz data (Sc71). 
TABLE II

GAMMA RAYS FROM

16 o $\left(n, n^{\prime} \gamma\right) 16$ O REACTIONS

\begin{tabular}{ccc}
$\begin{array}{c}\mathrm{E}_{\gamma} \\
(\mathrm{MeV})\end{array}$ & $\begin{array}{c}\mathrm{E}_{\text {initial }} \\
(\mathrm{MeV})\end{array}$ & $\begin{array}{c}\mathbf{s}_{\text {final }} \\
(\mathrm{MeV})\end{array}$ \\
\hline 8.872 & 8.872 & 0 \\
7.119 & 7.119 & 0 \\
6.917 & 6.917 & 0 \\
6.131 & 6.131 & 0 \\
4.949 & 11.080 & 6.131 \\
4.163 & 11.080 & 6.917 \\
3.833 & 10.952 & 7.119 \\
2.741 & 8.872 & 6.131 \\
2.208 & 11.080 & 8.872 \\
1.955 & 8.872 & 6.917 \\
1.753 & 8.872 & 7.119 \\
$0.510^{8}$ & 6.050 & 0
\end{tabular}

Each $6.650^{\circ} 0$ transition is assumed to produce two $0.51-\mathrm{MeV}$ annihilation photons.

The ${ }^{16} 0$ nucleus has two peculiar properties that should be noted. First, the $6.050 \mathrm{MeV}$ first excited state has $J^{\pi}=0^{+}$and can therefore decay to the $0^{+}$ ground state only by internal pair-productioll. Since provision has not been made in the ENDF/B system to ind lcate prompt electron decay following $\left(n, n^{\prime}\right)$ reactions, we were not able to include in the ENDF/B files the energy deposited by the electron-positron pair. The annihilation photons from the positron, however, do appear in the photon-production files with the appropriate threshold and cross section.

The second property of ${ }^{16} 0$ that should be noted deals with the relatively low threshold for the $\left(n, n^{\prime} \alpha\right)$ reaction. States above $7.161-$ MeV excitation are unstable to alpha emission (see Fig. 9); however, because both ${ }^{12} \mathrm{C}$ and the alpha particle have $0^{+}$ ground states, only states in 160 with parity equal to $(-1)^{\tilde{J}}$ can decay to the ground state of ${ }^{12} \mathrm{C}$. The $8.872-, 10.952-$, and $11.080-\mathrm{MeV}$ states do not satisfy this criterion and therefore de-excite by photon emission. Thus, the $\left(n, n^{\prime} \alpha\right)$ reaction is unimportant below $10 \mathrm{MeV}$ although its threshold occurs at 7.61 MeV. Above $11.605-\mathrm{MeV}$ excitation, states in 160 can alpha-decay to the $2^{+}$first-excited level of ${ }^{12} \mathrm{C}$ witiout the above restriction, and we have assumed that states in this region decay $100 \%$ by particle emission.

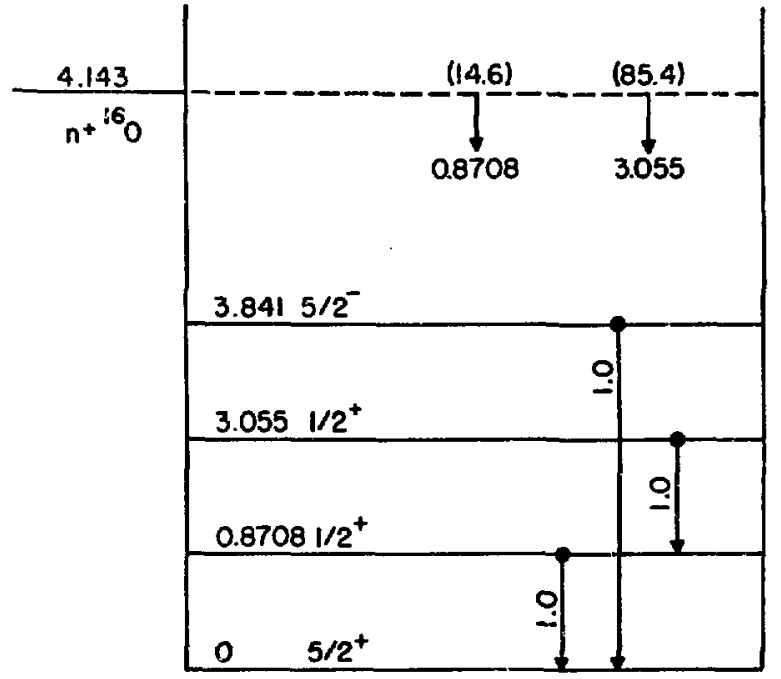

170

Fig. 8. Decay scheme and brenching ratios for ${ }^{17} 0$. The transitions that occur following thermal neutron captures are given in parentheses at the top of the diagram in photons per 100 captures.

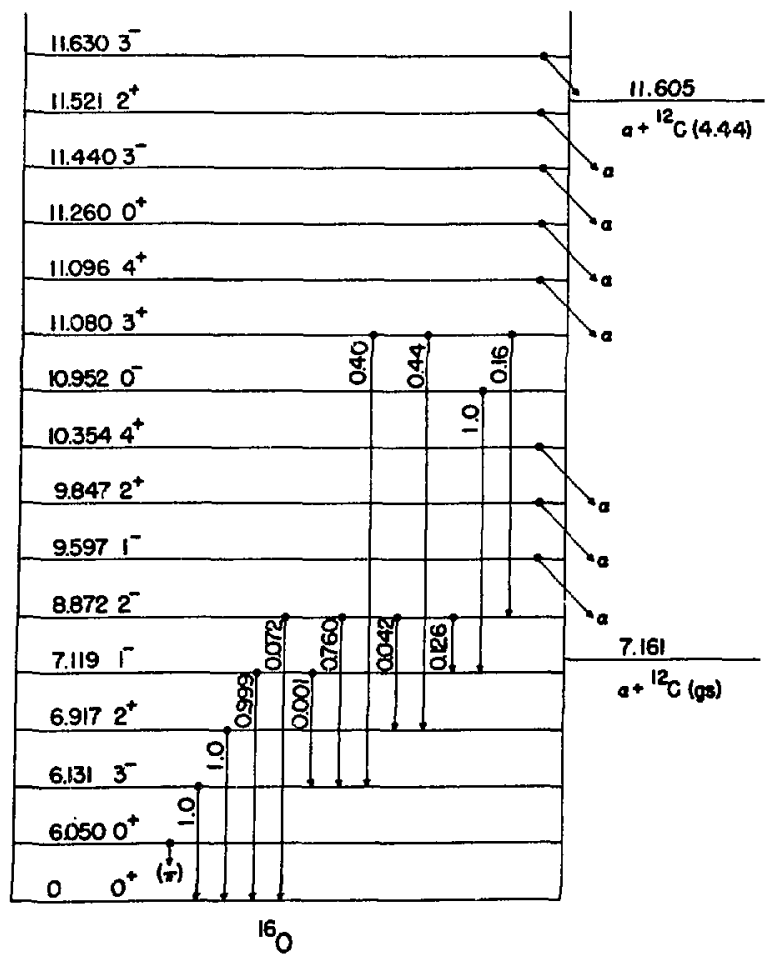

Fig. 9. Energy level decay scheme for 160 . 


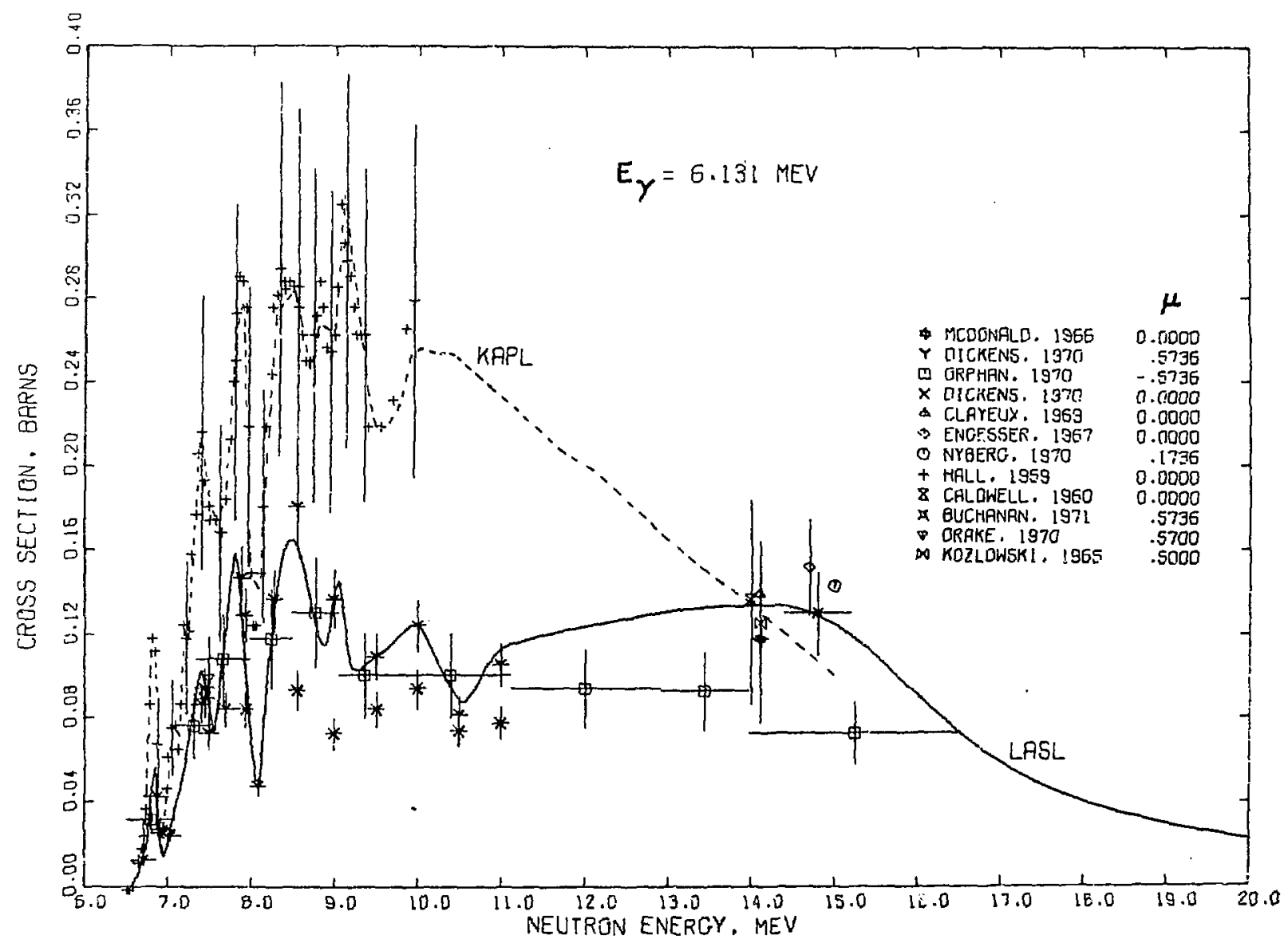

Fig. 10. Measured and evaluated $\left(n, n^{\prime} y\right)$ cross section for the 6.131-MeV photon.

The evaluated photon-production cross section for the ground-state transition from the $6.131-\mathrm{MeV}$ level is comparea in Fig. 10 to the KAPL evaluation* (s165) and to the available experimental data. A11 the measurements in Fig. 10 are single-angle $(\mu=\cos \theta)$ differential results that have been multiplied by $4 \pi$. The LASL curve is besed mainly on $55^{\circ}$ measurements made by Dickens and Perey (Di70) below $11 \mathrm{MeV}$ and on a composite of several measurements near $15 \mathrm{MeV}$. The single datum at $7.5 \mathrm{MeV}$ by Drake et al. (DrTO) is part of a complete angulardistribution measurement. The Drake data indicate that a significant error $\left(\sim^{4}\right)$ is introduced at 7.5 $\mathrm{MeV}$ by assuming the integrated cross section to be $1, \pi \sigma\left(55^{\circ}\right)$. This assumption is made throughout the

* Because photon-production data are not included in the KAPL evaluation, the dashed curve of Fig. 10 was computed from the KAPL $\left(n, n^{\prime}\right)$ cross sections and the decay scheme of Fig. present evaluation because very few photon angular distribution measurements exist for oxygen, and we did not perform a detailed theoretical analysis. The differences between the $55^{\circ}$ and $90^{\circ}$ measurements of Dickens and Perey (DI7O) Indicate that the anisotropy of the 6.151-MeV photon persists at most neutron energies below $11 \mathrm{MeV}$. The KAPL curve in Fig. 10 is apperently besed on the 1959 measurements of Hall et al. (Ha59) and is roughly a factor of two higher then the IASL curve below $11 \mathrm{MeV}$.

Similar comparisons are given in Figs. 11 and 12 for the ground-state transitions from the 6.917and 7.119-MeV levels. Figure 13 includes the photonproduction cross sections for the 1.753- and 2.741MeV photons, both of which result from de-excitation of the $8.872 \mathrm{MeV}$ level in ${ }^{16} \mathrm{O}$, and the cross section for the $2.208-\mathrm{MeV}$ photon from the $11.080-\mathrm{MeV}$ level is given in Fig. 14. The KAPL evaluation (5165) is generally higher than our results in Figs. 11-14. 


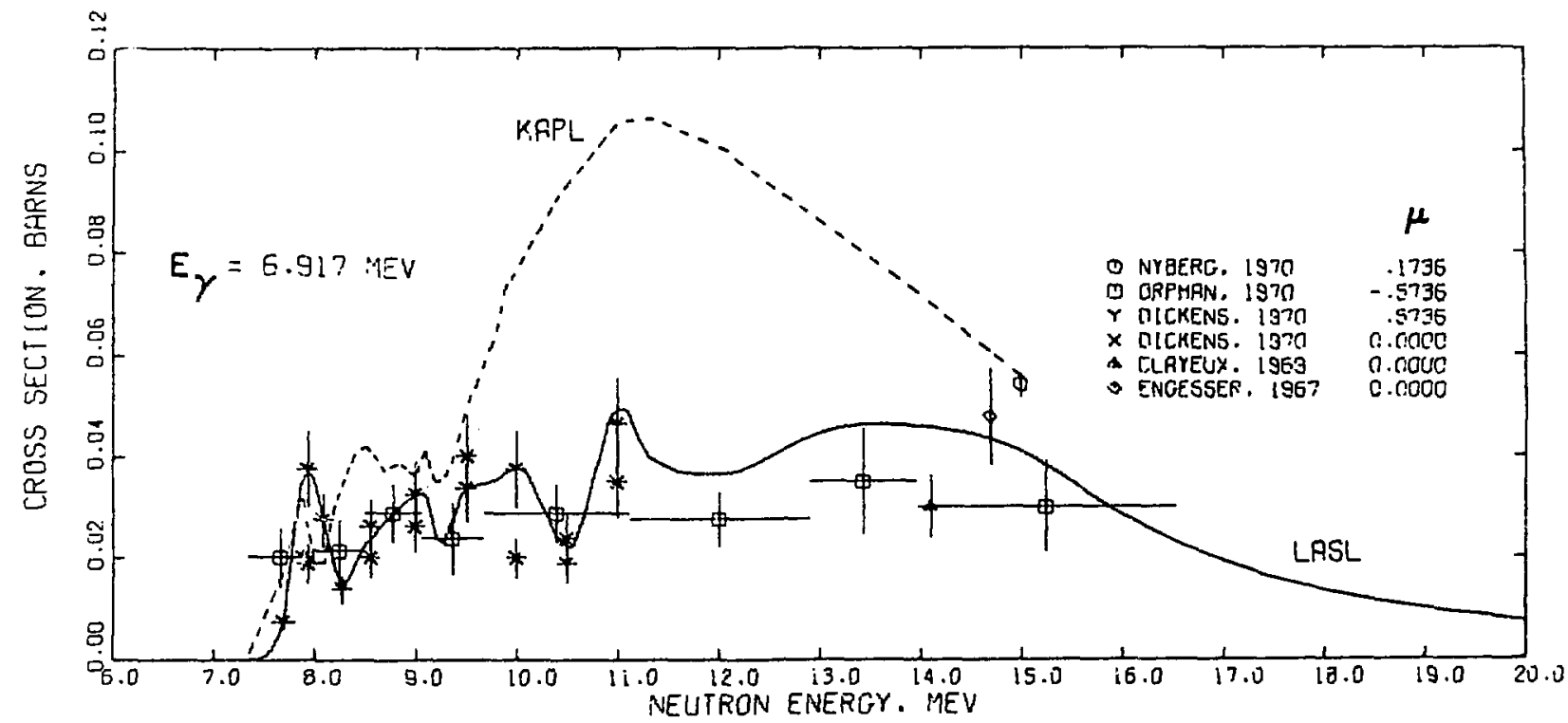

Fig. 11. Measured and evaluated $\left(n, n^{\prime} y\right)$ cross section for the 6.917 -MeV photon.

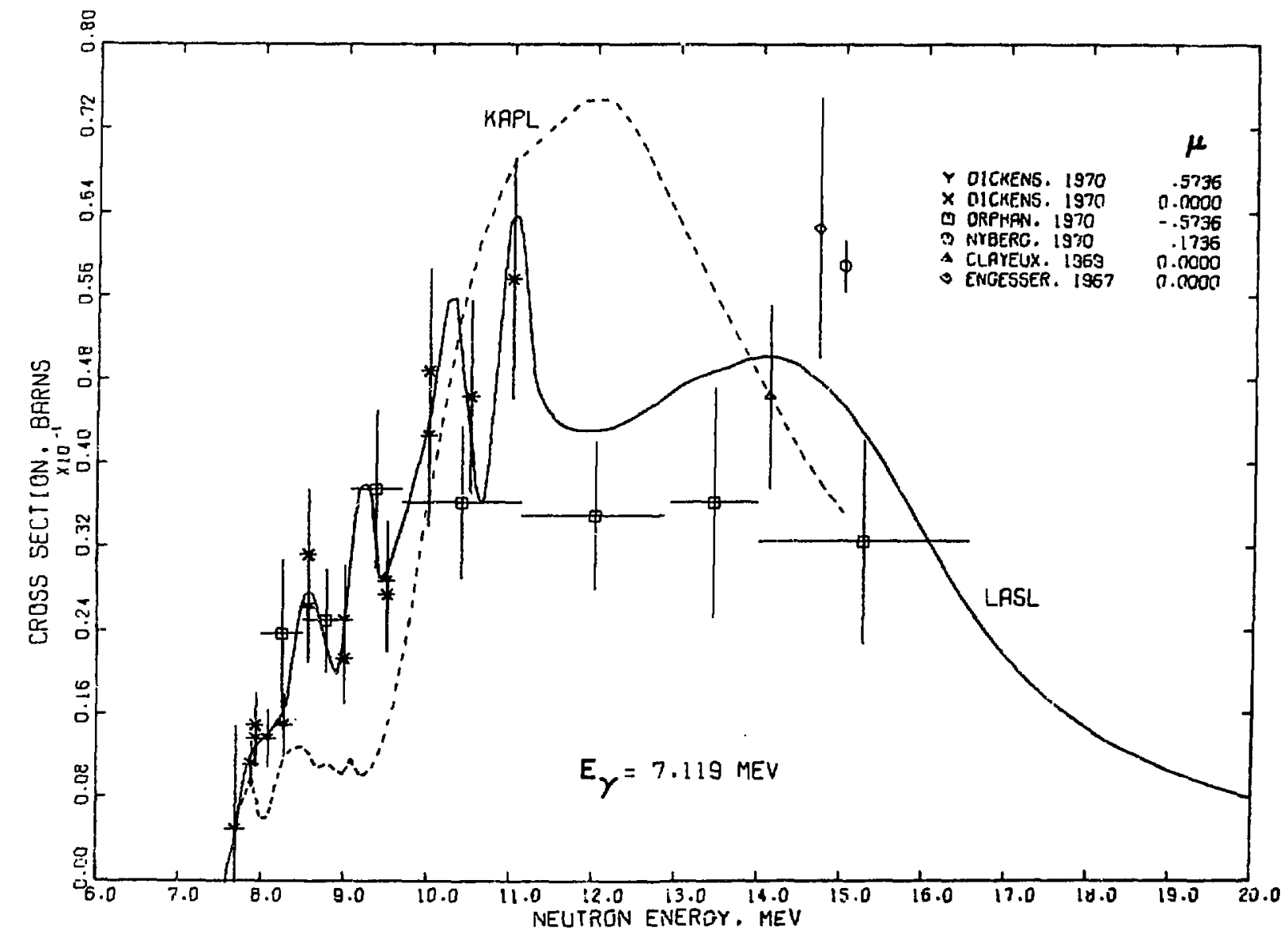

Fig. 12. Measured and evaluated $\left(n, n^{\prime} \gamma\right)$ cross section for the $7 \cdot 119$ HeV photon. 
The $55^{\circ}$ and $90^{\circ}$ measurements made by Dickens and Perey (D170) indicate that at most neutron energies the anisotropy in the angular distributions for tilese photons is significantly less than for the 6.131-MeV photon.

The $\left(n, n^{\prime}\right)$ excitation cross sections for the $6.131-, 6.917-, 7.119-$, and $8.872-\mathrm{MeV}$ levels that resulted from our analysis of $\left(n, n^{\prime} \gamma\right)$ measurements are given in Fig. 15. Beyond $15 \mathrm{MeV}$, the shapes of the curves are taken from compound-nucleus reactiontheory calculations made with the code comirc (Du71). The results shown for the $6.052-\mathrm{MeV}$ level also result from COMNUC calculations, normalized with the same fector required to bring the calculated excitation cross sections for the photon-producing levels into approximate agreement with the $\left(n, n^{\prime} \gamma\right)$ measurements. Similarly, the curves shown in Figs. $1=17$ for levels with excitation energy between 8.9 and $13 \mathrm{MeV}$ are based on camruc calculations. The normalization for

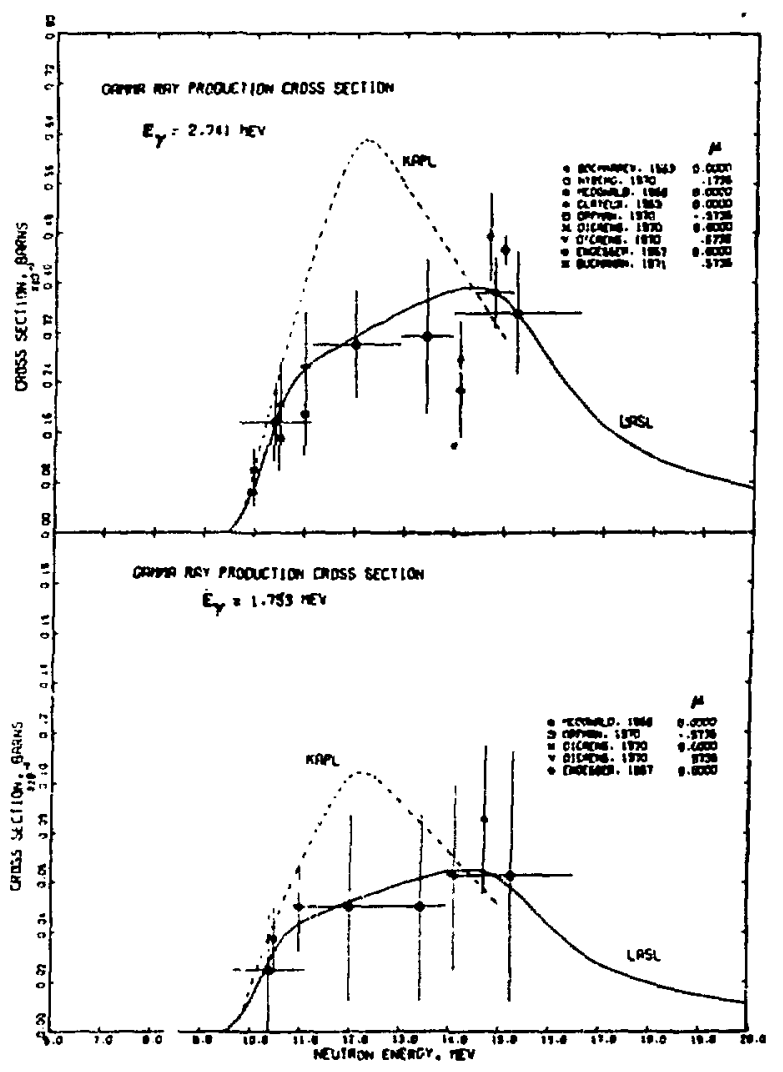

F1g. 15. Measured and evaluated $\left(n, n^{\prime} \gamma\right)$ cross sections for the 1.753 - and $2.741-\mathrm{MeV}$ photons resulting from the $8.872 \rightarrow 7.119 \mathrm{MgV}$ and $8.872 \rightarrow 6.131-\mathrm{MeV}$ transitions in 160 . these calculations was chosen so that the total crosa section minus the reaction cross section near $14 \mathrm{MeV}$ resulted in an elastic cross section consistent with measurements (see Fig. 35 in Sec. 2.7).

The sums of the excitation cross sections for the 6.05- and 6.13-Mev levels and the 6.92- and 7.12-MeV levels are in excellent agreement with direct measurements near $14 \mathrm{MeV}$ made by Bauer et $a 1$. (Ba63) and McDonald et al. (Mc66a). The excitation cross section for the $8.87-\mathrm{MeV}$ level deduced from the $\left(n, n^{\prime} \gamma\right)$ measurements 1s, horever, higher by roughly a factor of 2 than the direct measurement of McDonald et al. (Mc56a).

The total inelastic cross section that results from the above anslysis is compared in Fig. 19 to the evaluation of Slaggie and Reynolds ( $\$ 165$ ). The present results are substantially lower than the KAPL curve at energies below $13 \mathrm{MeV}$, mainly reflecting the difference between the older $\left(n, n^{\prime} \gamma\right)$ measurements of Hall et al. (Ha59) and the newer measurements of Dickens and Perey (D170) and Orphan et al. (or7o).

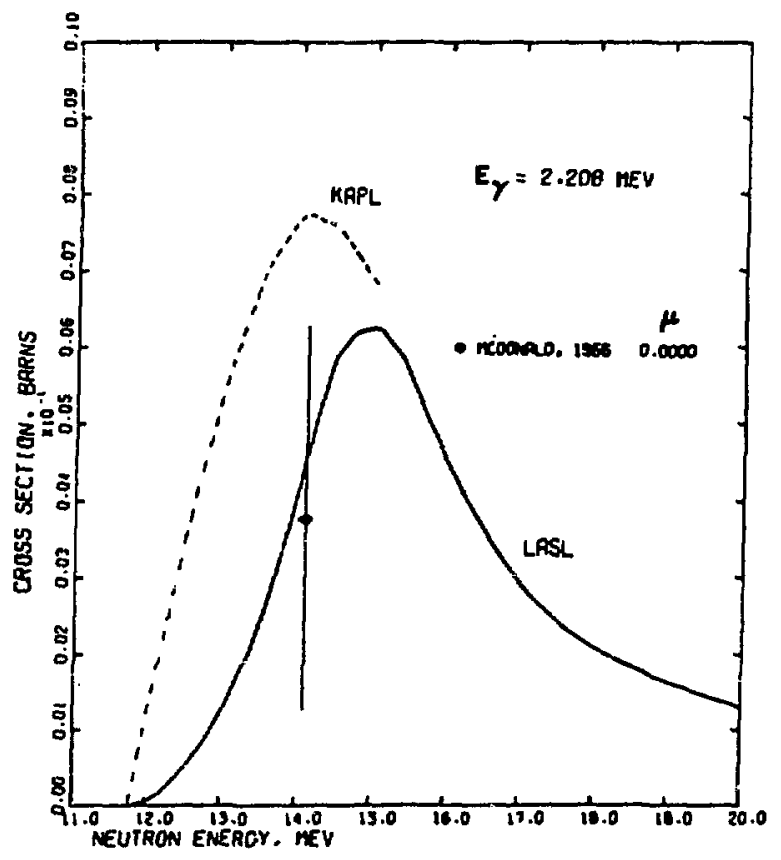

Fig. 14. Measured and evaluated $\left(n, n^{\prime} \gamma\right)$ cross section for the 2.208-MeV photon resulting from the $11.080 \rightarrow 8.872-\mathrm{MeV}$ transition in 160 . 


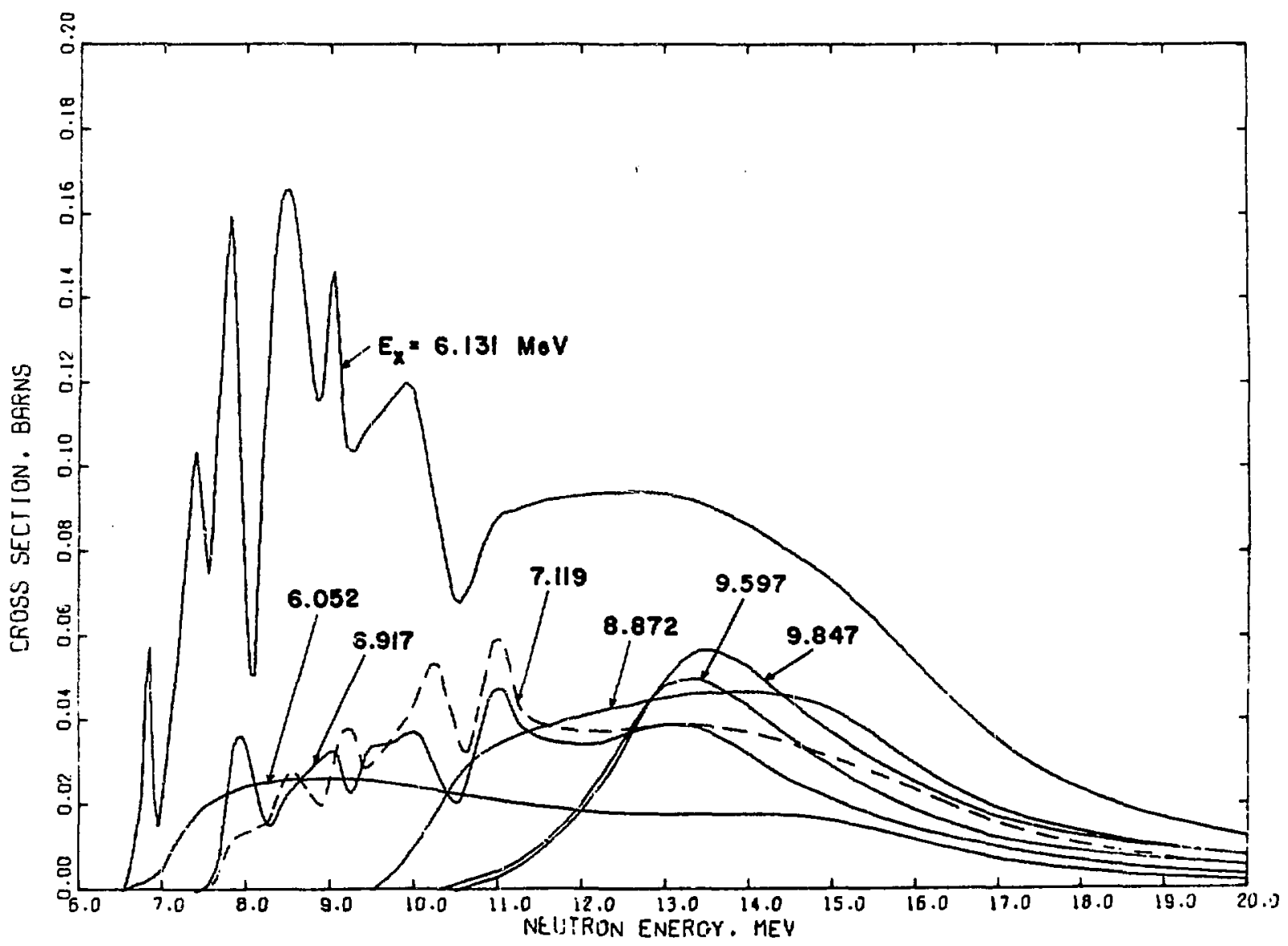

F1g. 15. Evaluated cross sections for inelastic scattering to levels in 160 with $E_{x}<10 \mathrm{MeV}$.

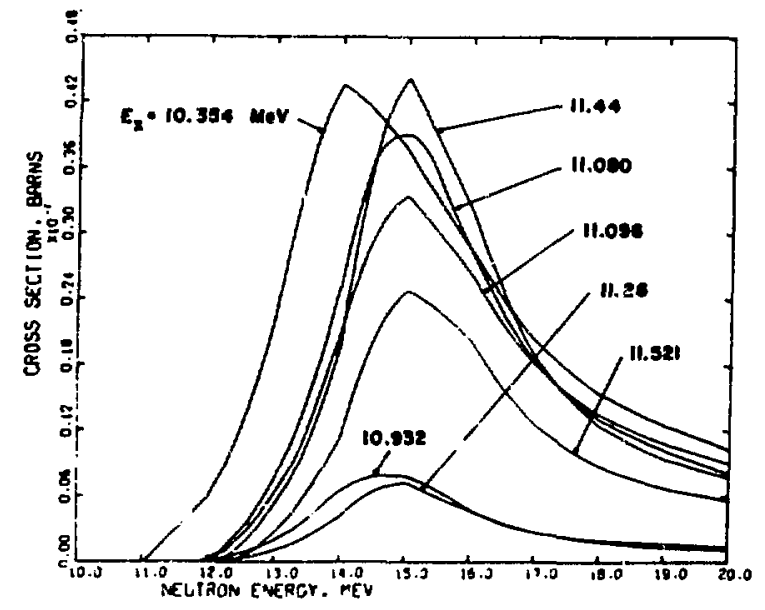

FIg. 16. Evaluated cross sections for inelastic scattering to levels in $16_{0}$ with $E_{x}$ between 10.354 and $11.521 \mathrm{MeV}$.

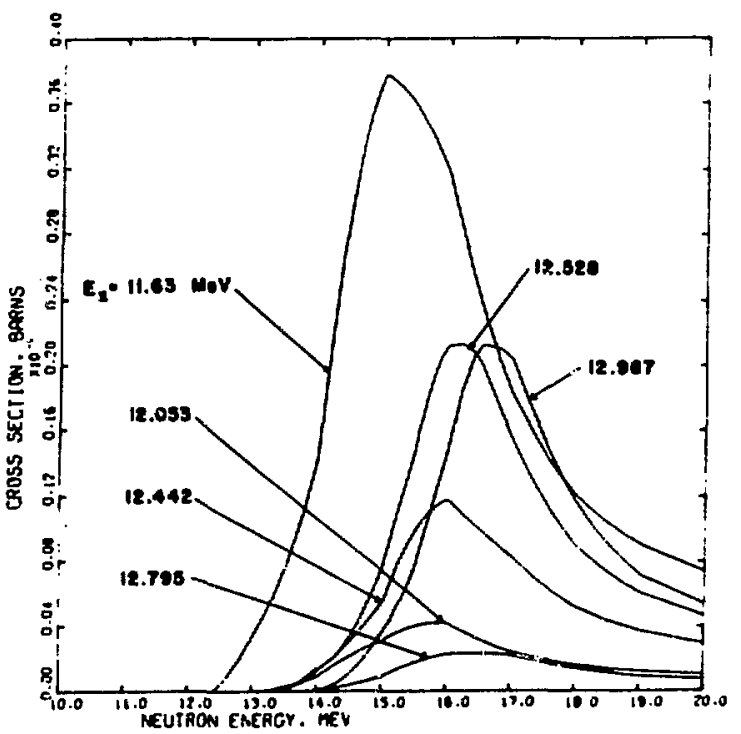

Fig. 17. Evaluated cross sections for inelastic scattering to levels in 160 with Ex between 11.63 and $12.967 \mathrm{MeV}$. 
2.3.2. The ${ }^{16}\left(n, n^{\prime}\right)$ Cross section for $E_{x}\left(^{16} 0\right)$ $>13 \mathrm{MeV}$. At excitation energies above $13 \mathrm{MeV}$, the level structure in ${ }^{16} \mathrm{O}$ becomes increasingly less certain, and a simple evaporation model was used to estimate the relative $\left(n, n^{\prime}\right)$ cross section to levels in this region. We used an expression of the form

$$
\sigma_{n, n^{\prime}} \propto\left(E_{0}-E_{x}\right) \exp \left(E_{x} / T\right)
$$

where $E_{0}$ is the total energy avallable in the centerof-mass system, $E_{x}$ is the excitation energy in ${ }^{16} \mathrm{O}$, and $T$ is the nuclear temperature. A value of $2 \mathrm{MeV}$ was used for the temperature. The relative cross sections generated in this manner were nomalized so that the nonelastic cross section agreed with the total and elastic cross sections. These results are represented as discrete $\left(n, n^{\prime}\right)$ reactions to $0.3-\mathrm{MeV}$ wide bands of excitation energy in ${ }^{16} \mathrm{O}$ and are given in F1g. 18. This representation was used rather than the more usual form of continuous energy spectra to permit more accurate cal.culation of the effects of center-of-mass motion on the neutron angular distributions (Y०72).

2.4. The $\left.{ }^{16} O(n, p)\right)^{16}$ and ${ }^{16} O(n, p y)^{16}{ }_{N}$ cross sections The evaluated $(n, p)$ cross section of slaggle and Reynolas ( 5165 ) below $15 \mathrm{MeV}$ was adopted in the present study. From 15 to $17 \mathrm{MeV}$, we used experimental data to defermine the $(n, p)$ cross section, and above $17 \mathrm{MeV}$ ve jolned a shape calculated with the code canvuc to the the lower-energy results. The evaluated curve is compared to tine available measurements in Fig. 20. Most of the bigh energy

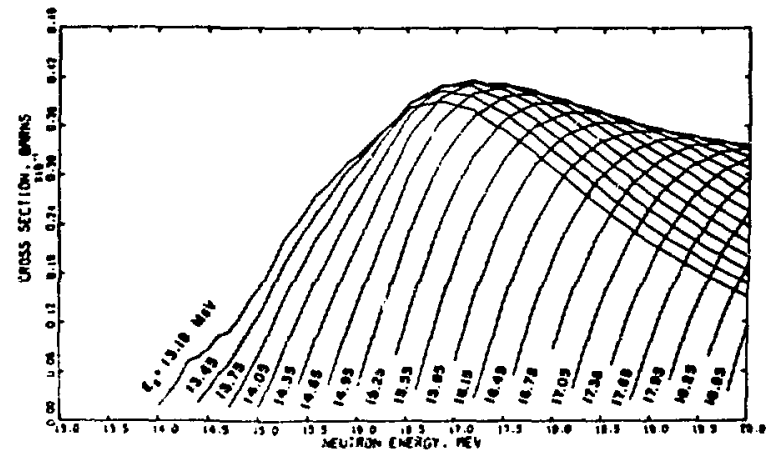

Fig. 18. Fvaluated $\left(n, n^{\prime}\right)$ cross sections to groups of levels in ${ }^{16} \mathrm{O}$ ith $E_{x}$ between 15 and $19 \mathrm{MeV}$. Fach $0.3 \mathrm{MeV}$ in excitation energy is represented as a single fictitious leve] at the midpoint energy. measurements (e.g., Bo67, De60, De62, Ka62, Ma54, Mi66, Pa53, Pr66, Se62) result from activation studies; the evaluated curve therefore does not include $(n, p)$ reactions to particle-unstable states* of ${ }^{16} \mathrm{~N}$.

Several low-energy photons are produced by the ${ }^{16} \mathrm{o}(\mathrm{n}, \mathrm{p} \gamma)^{16} \mathrm{~N}$ reaction, as indicated in the ${ }^{16} \mathrm{~N}$ level decay scheme of F1g. 21. No experimental data are avaliable on these transitions, and the individual $(n, p)$ level excitation cross sections are not included explicitly in the evaluation. We estimated the $(n, p \gamma)$ cross sections, however, by distributing the evaluated $(n, p)$ cross section of Fig. 20 among the particle-stable states of ${ }^{16} \mathrm{~N}$, assuming the population of each to be proportional to $(2 \mathrm{~J}+1)$. Table III gives a sumary of the $(n, p \gamma)$ transitions included in the evaluation. Two of the transitions have been combined, as indicated.

TABIE III GAMRA RAYS FROM
$160(n, p \gamma) 16_{N}$ REACTIONS

$\begin{array}{lll}\begin{array}{c}E_{\gamma} \\ (\mathrm{MeV})\end{array} & \begin{array}{c}E_{\text {initial }} \\ (\mathrm{MeV})\end{array} & \begin{array}{c}E_{\text {final }} \\ (\mathrm{MeV})\end{array} \\ 0.397 & 0.397 & 0 \\ 0.292 & \left\{\begin{array}{ll}0.297 & 0 \\ 0.397 & 0.121\end{array}\right\} \\ 0.120 & \left\{\begin{array}{ll}0.121 & 0 \\ 0.397 & 0.297\end{array}\right\}\end{array}$

In this context we exclude beta emission in defining "particle-stable" levels.

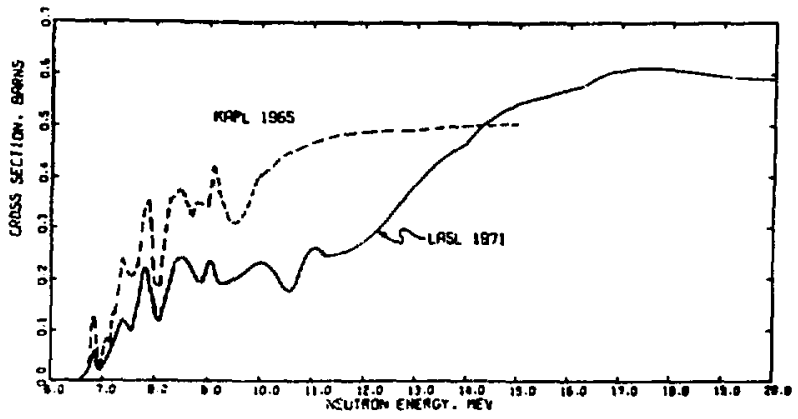

Fig. 19. Fvaluated total inelastic cross section from 6 to $20 \mathrm{MeV}$. The LASL curve includes $\left(n, n^{\prime} \alpha\right)$ and $\left(n, n^{\prime} p\right)$ contributions. 


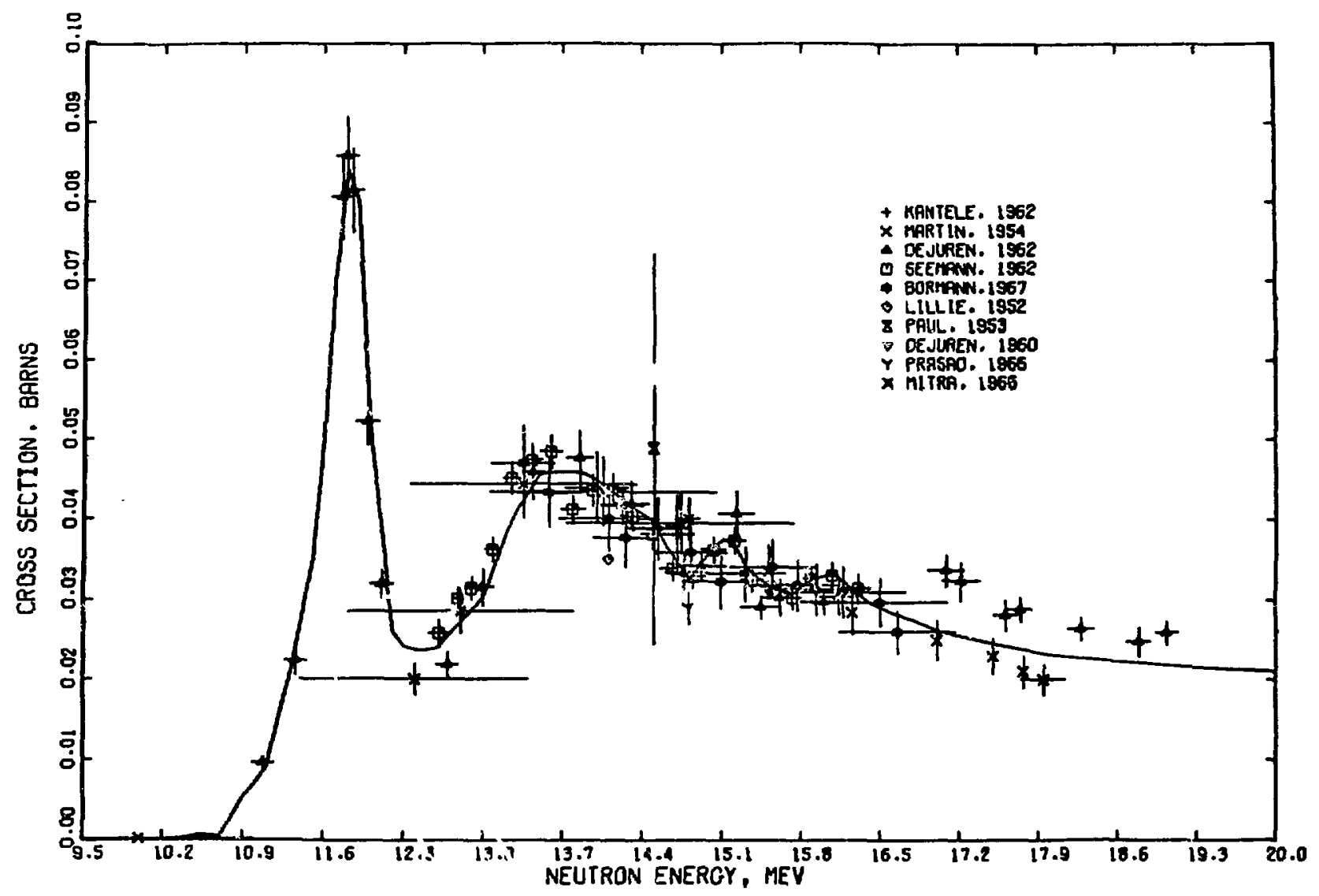

Fig. 20. Measured and evaluated total $\left(n, J_{1}\right)$ cross section for 160 from 10 to 20 MeV.

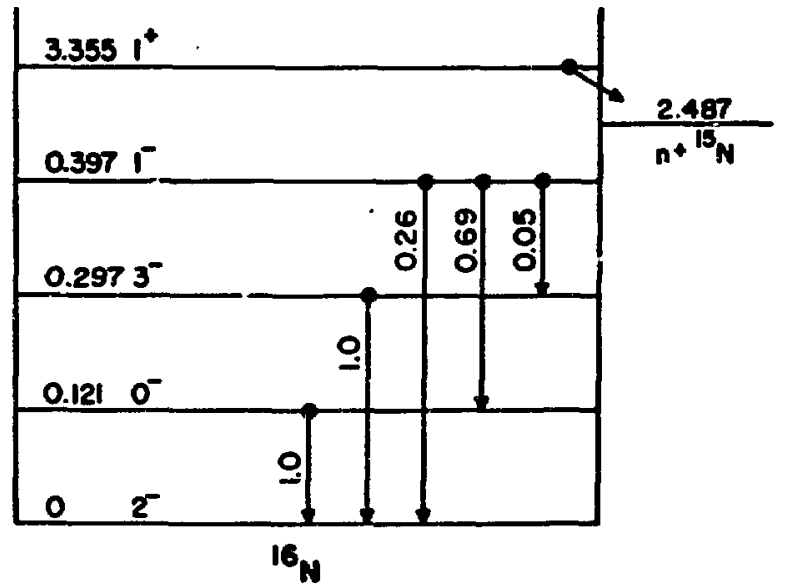

Fig. 21. Energy-level decay scheme for $16 \%$.

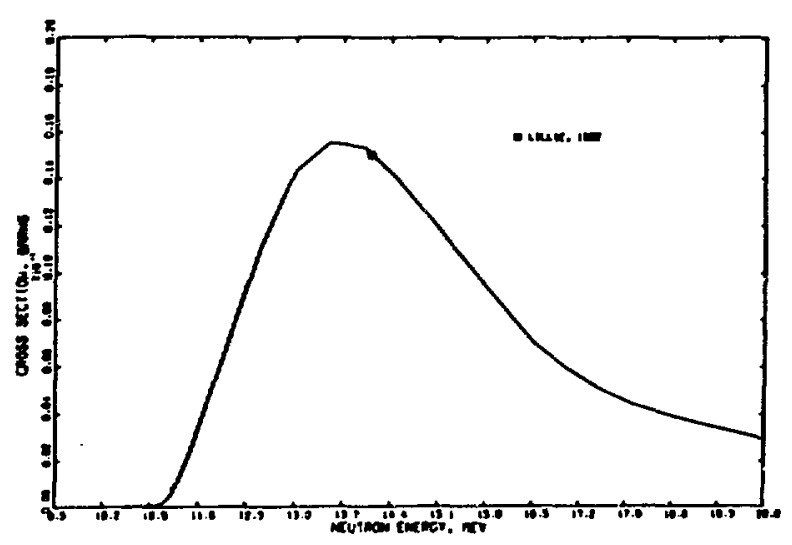

FIg. 22. Measured and graluated total $(n, d)$ cross section for 160 from 10 to 20 iev. 
2.5. The ${ }^{16} O(n, d)^{15} N$ Cross Section

The $(n, d)$ cross section is given in Fig. 2e. The evaluated curve is based on a compound-nucleus reaction-theory calculation with the code canvuc, normalized to the lone measurement by Lillie (L152) near $14 \mathrm{MeV}$. Because the threshold for the $(n, d y)$ reaction does not occur until $16.1 \mathrm{MeV}$, photon production from $(n, d)$ reactions was ignored. 2.6. The ${ }^{16} \mathrm{O}(\mathrm{n}, \alpha)^{13} \mathrm{c}$ and ${ }^{16} \mathrm{o}(\mathrm{n}, \alpha \gamma)^{13} \mathrm{C}$ cross sections. At excitation energies higher than $4.947 \mathrm{MeV}$, ${ }^{13} \mathrm{C}$ levels decay predominantly by neutron emission, as indicated in the decay scheme of Fig. 23. The excitation cross sections to the ground and first three excited states are included in the present evaluation, and the sum of these is given as the total $(n, a)$ cross section. The $(n, \infty)$ cross section through the higher levels is lumped with the $\left(n, n^{\prime} \alpha\right)$ eross section discussed in Sec. 2.3.2. The photon transitions included in this study are given in Tabla IV.

Figure als shors the $\left(n, \alpha_{0}\right)$ cross section from threshold to $6 \mathrm{MeV}$. The Slaggie and Reynolds (5165) evaluation was adopted in this region, and the
TABLE IV

16 GAMMA BAYS FROM

\begin{tabular}{|c|c|c|}
\hline $\begin{array}{r}\mathrm{E}_{y} \\
(\mathrm{MeV})\end{array}$ & $\begin{array}{c}E_{\text {initial }} \\
(\mathrm{MeV})\end{array}$ & $\begin{array}{l}E_{\text {finel }} \\
(\mathrm{MeV}) \\
\end{array}$ \\
\hline .854 & 3.854 & 0 \\
\hline 684 & 3.684 & 0 \\
\hline 086 & 3.086 & 0 \\
\hline & $\{3.854$ & $3.086\}$ \\
\hline & $\{3.684$ & $3.086 \mathrm{~J}$ \\
\hline 170 & 3.854 & 3.684 \\
\hline
\end{tabular}

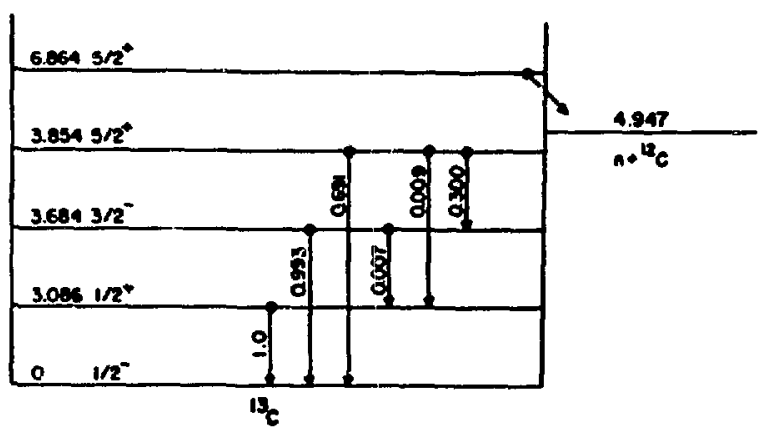

Fig. 23. Energy-level decay sckeme for ${ }^{13} \mathrm{c}$.

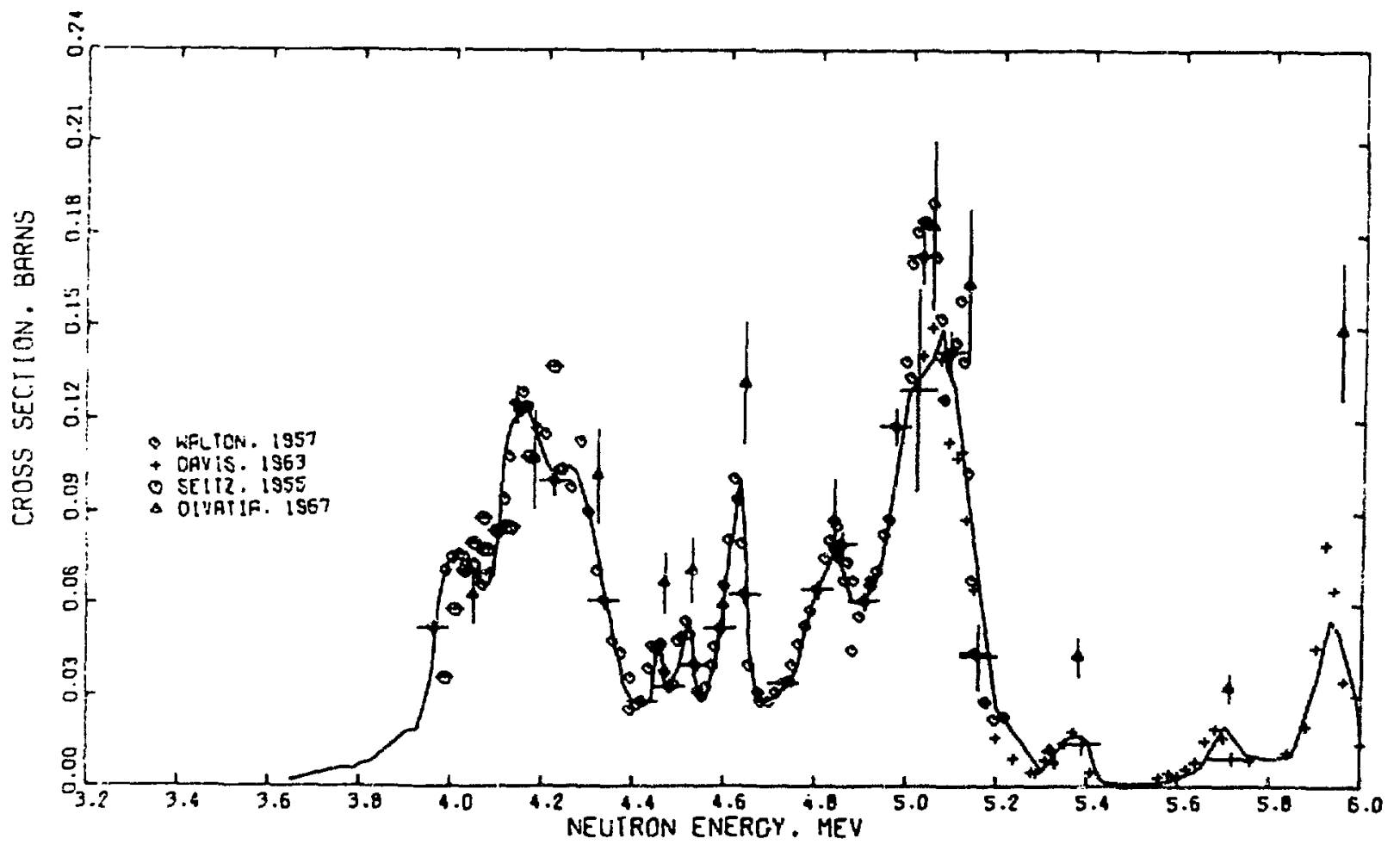

Fig. 24. Measured and evaluated $\left(n, a_{0}\right)$ cross section between 3.2 and 6.0 Mev. 
agreement with the avallable measurements is reasonable. Above $6 \mathrm{MeV}$, we reevaluated the $\left(n, \alpha_{0}\right)$ reaction, and the results are compared to experiment in Fig. 25. At higher energles the curve is based mainly on the weasurements of Sick et al. (S168).

The $\left(n, \alpha_{1}\right)$ cross section below $15 \mathrm{MeV}$ was determined from measurements of the direct $\left(n, \alpha_{1}\right)$ cross section to the $3.086 \mathrm{MeV}$ level and from measurements of the ground-state photon transition from that level, as given in Fig. 26. The excitation cross sections to the 3.684- and 3.854-MeV levels are based on measurements of the ground-state photons below $15 \mathrm{MeV}$, using the decay scheme shown in Fig. 23, and the resulting photon-production cross sections are given In Figs. 27 and 28. At energies above $15 \mathrm{MeV}$, we obtained the $(n, a)$ cross sections to the first three excited levels by dividing the total $(n, a)$ cross section avalable to these livels, as measured by Sick et al. (S168) and shown in Fig. 29, anong the three states assuming each is populated in the same rat 10 as occurs near 15 yer.

The total $(n, \alpha)$ cross section is given by the solid curve in Fig. 30. The experimental results in the figure are actually measurements of the alphaemission cross section, and the rapid increase in the measurements above $12 \mathrm{MeV}$ is caused by the onset of the $\left(n, n^{\prime} \alpha\right)$ reaction. The difference between the
KAPL and LASL $(n, \alpha)$ curves occurs because part of the $\left(n, n^{\prime} \alpha\right)$ cross section was apparently included in the KAPL curve, whereas we chose to include that reaction in our $\left(n, n^{\prime}\right)$ files, designating alpha emission as the mode of decay of the residual nucleus.

The total alpha-emission cross section constructed from our $\left(n, n^{\prime} \alpha\right)$ and $(n, \alpha)$ cross sections is also given in Fig. 30 . At all energies above $13 \mathrm{MeV}$, our results are higher than the experimental data. It should be noted, however, that the lodenergy portion of the alpha spectrum is difficult to measure accurately, so the agreement is probably reasonable below $17 \mathrm{MeV}$. Above $17 \mathrm{MeV}$, however, the evaluated curve is too high, probably because proton decay folloring $\left(n, n^{\prime}\right)$ reactions [i.e., the $\left(n, n^{\prime} p\right)$ reaction] is competing more effectively with alpha decay than we have assumed. This problem was not discovered until the evalibation had been completed. The cross section for proton emission, corresponding to the sum of the total $(n, p)$ and $\left(n, n^{\prime} p\right)$ reactions, is given in Fig. 31, together with the alpha-emission cross section* and the total $\left(n, n^{\prime}\right)$ cross section to gamma-decaying levels. A slight increase in the $(n, n ' p)$ cross section with a corresponding decrease in $\left(n, n^{\prime} \alpha\right)$ would correct the problem above $17 \mathrm{MeV}$ in Fis. 30 .

*The structure in the alpha-emission cross section above $15 \mathrm{MeV}$ in $\mathrm{Fig}$. 31. is ertificifil and results from the particuiar representation that we used in the ENDF/B files.

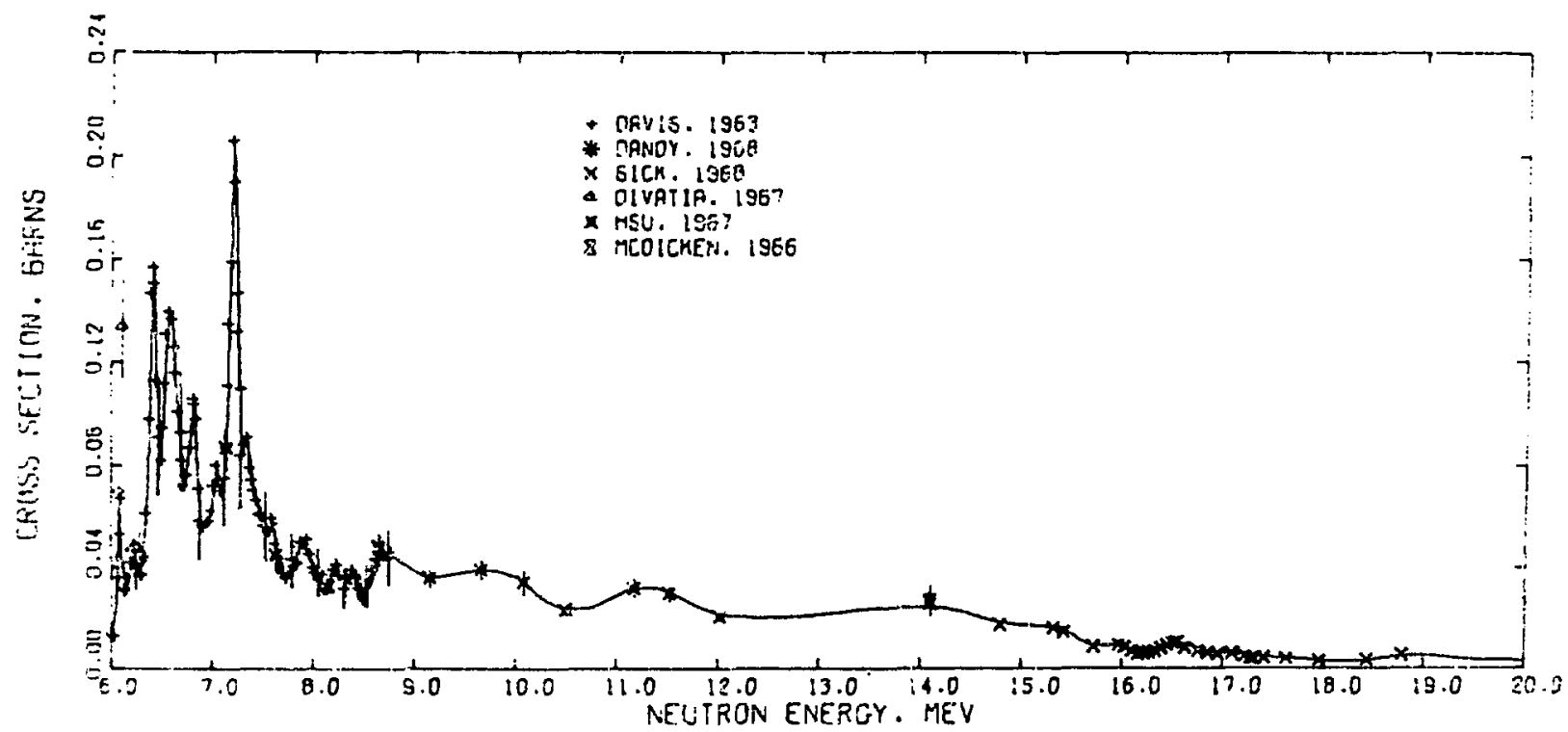

F1g. 25. Measured and evaluated $\left(n, a_{0}\right)$ cross section between 6 and 20 MeV. 


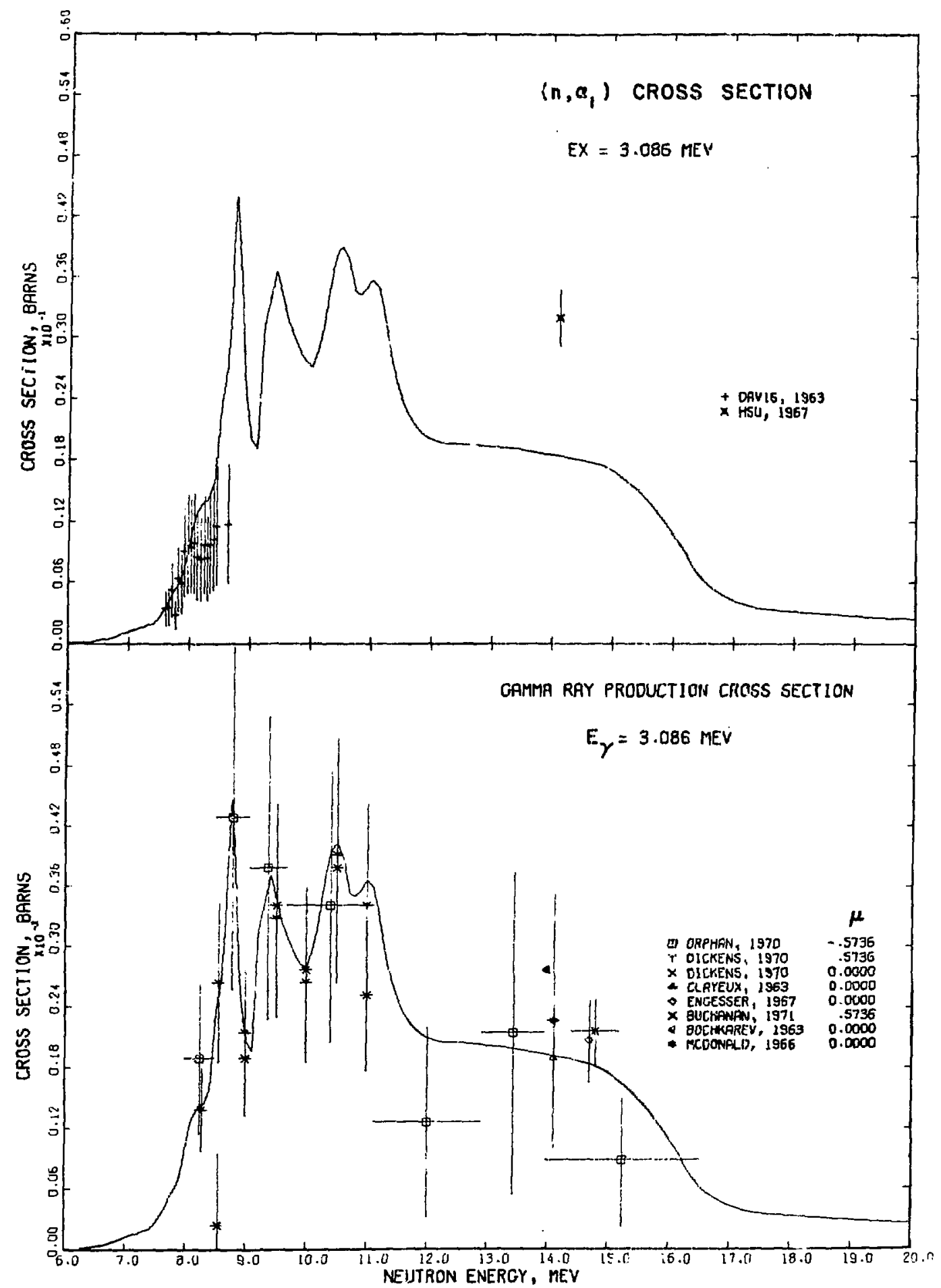

Fig. 26. Measured and evaluated $\left(n, \alpha_{1}\right)$ and $(n, \infty \gamma)$ cross sections for the 3.086-MeV level and around-state transition in ${ }^{13} \mathrm{C}$. 


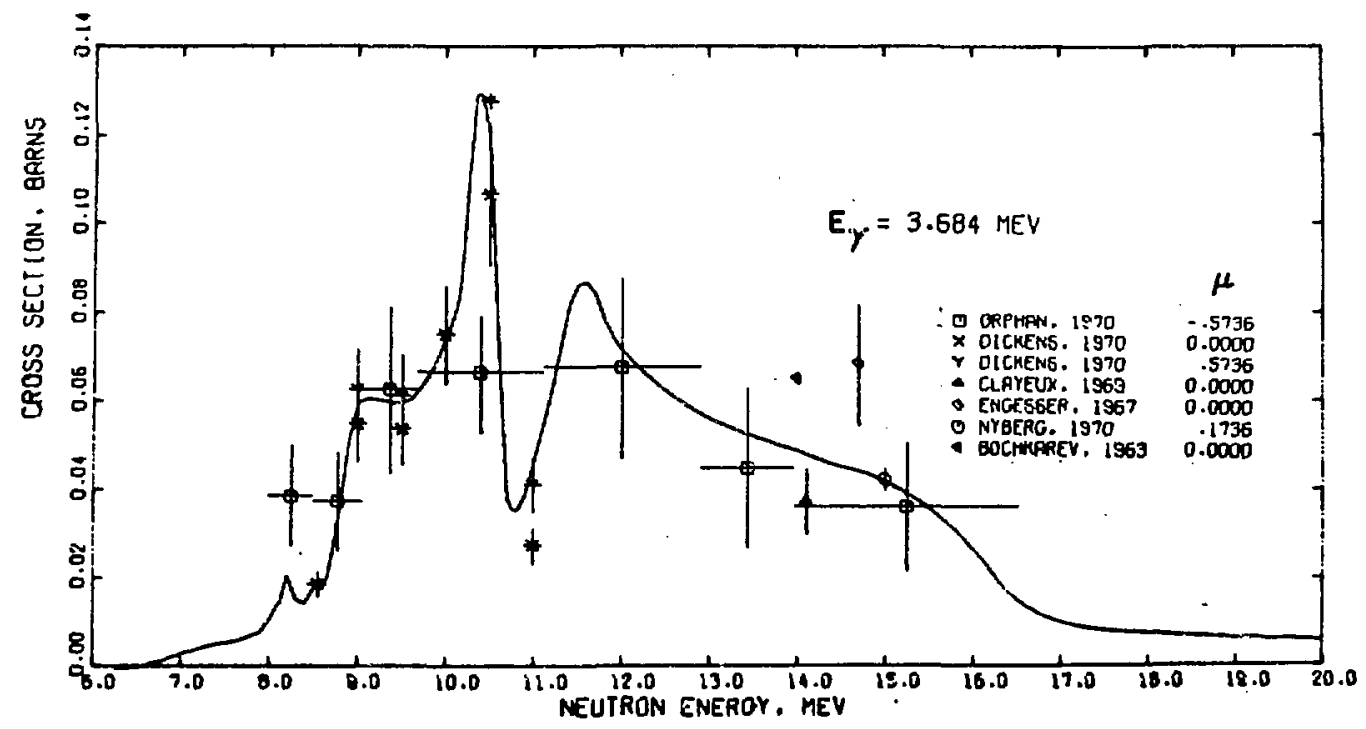

Fig. 27. Measured and evaluated $(n, \alpha \gamma)$ cross section for the 3.684-MeV photon.

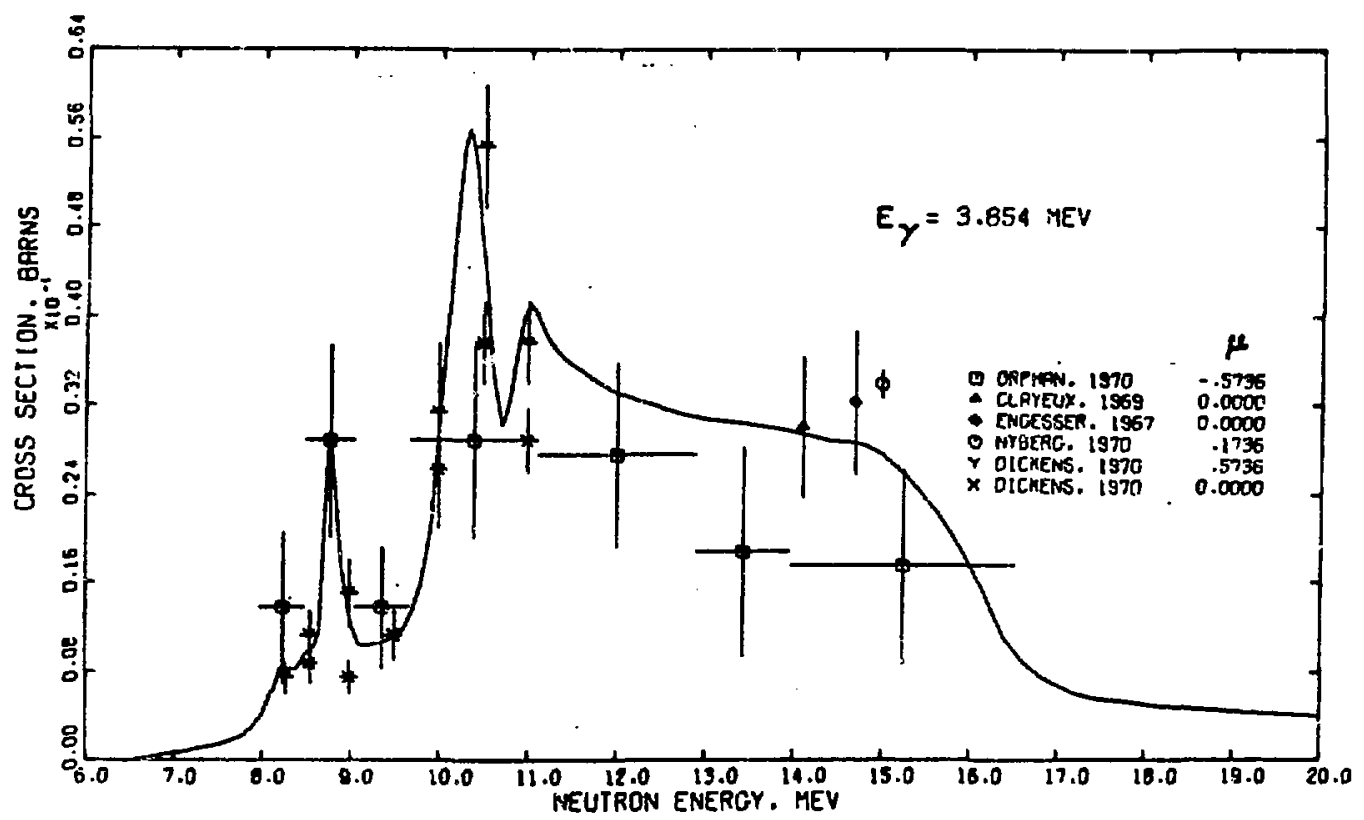

Fig. 28. Seasured and evaluated $(n, \alpha \gamma)$ cross section for the 3.854-MeV photon. 


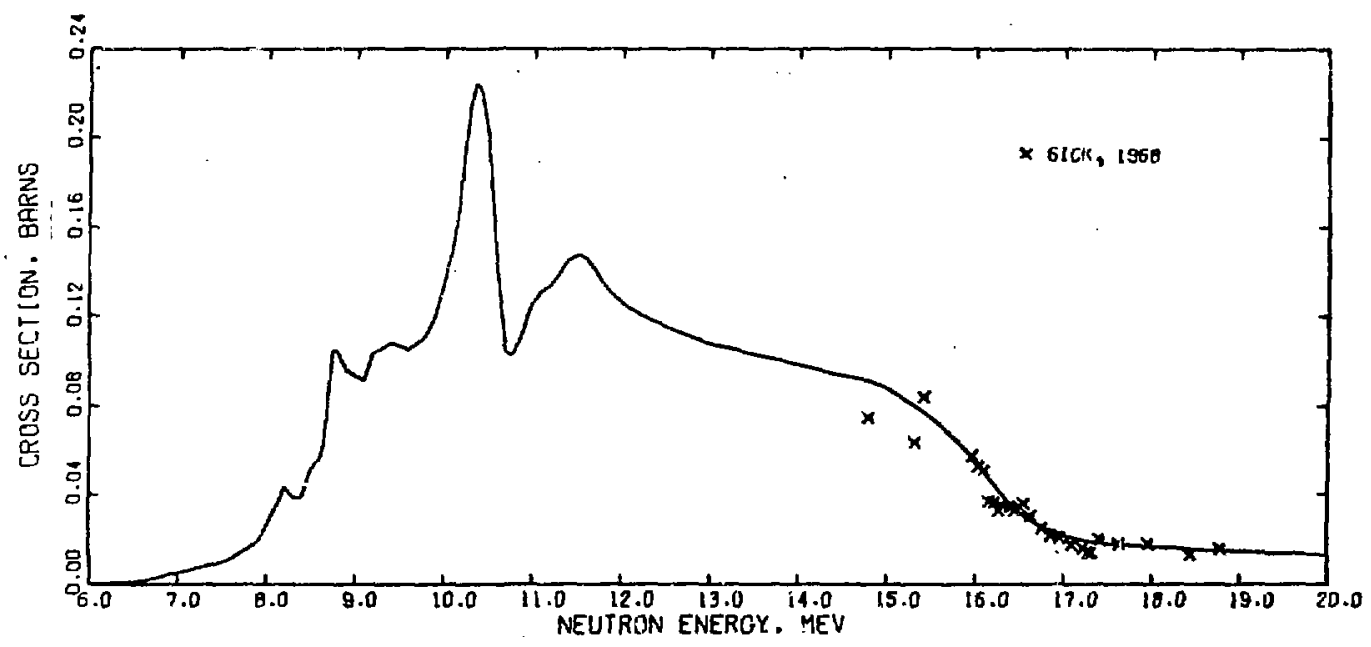

Fig. 29. Measured and evaluaţed composite $(n, \alpha)$ cross section to the first three excited levels of ${ }^{13} \mathrm{C}$.

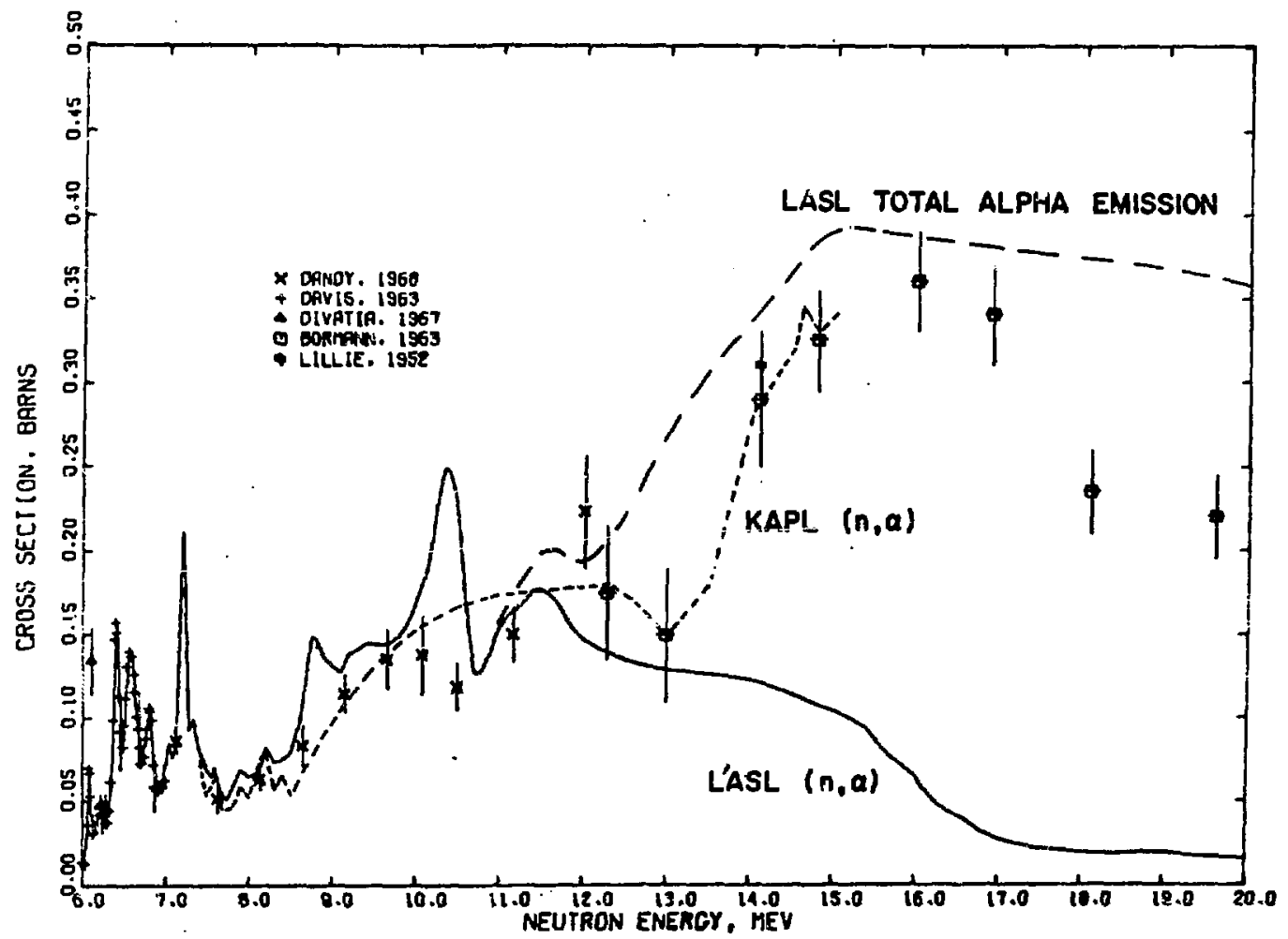

Fig. 30. Measured and evaluated total alpha emission cross aection compared to the IASL and KAPL $(n, \alpha)$ evaluations. 


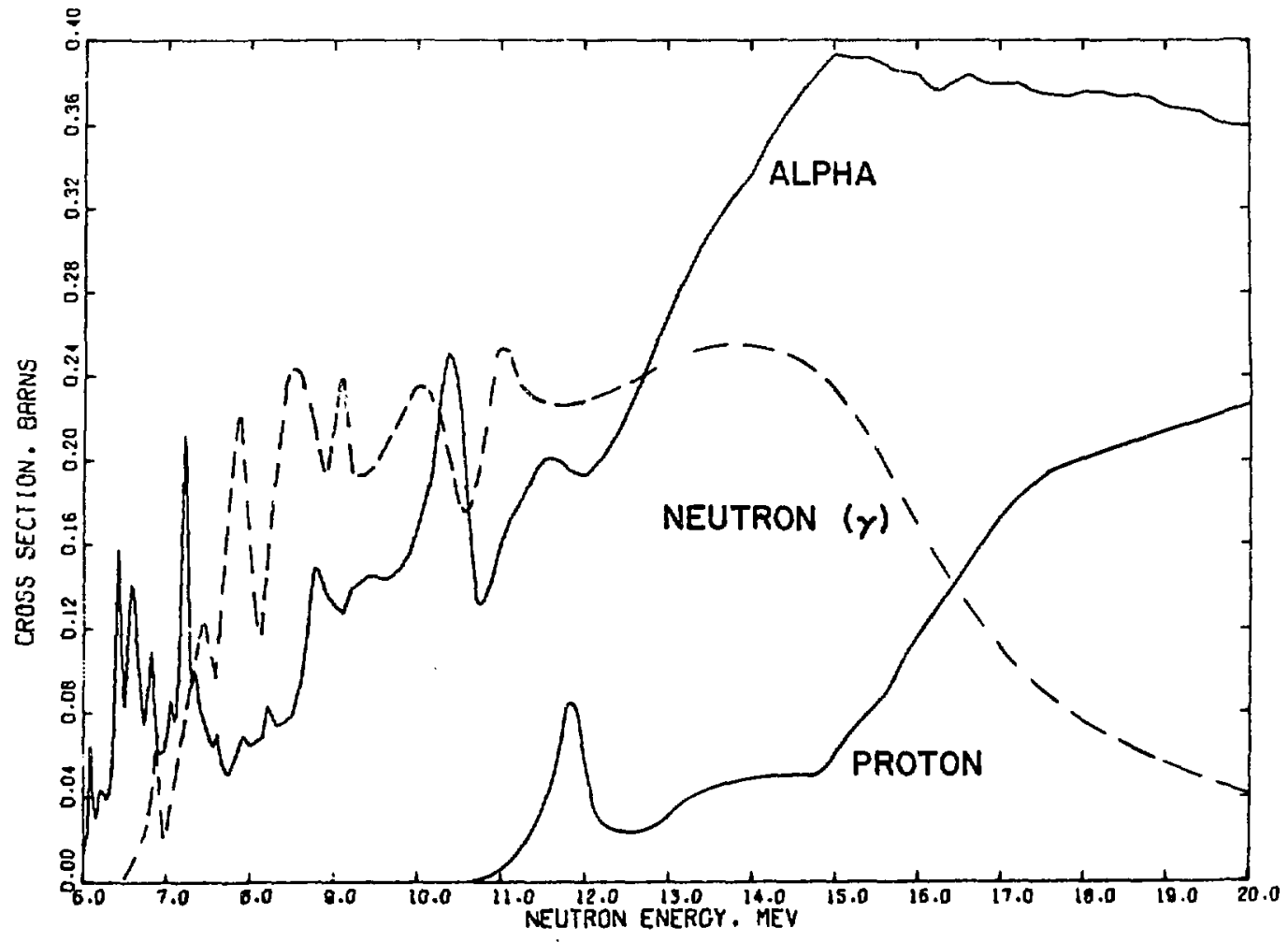

Fig. 31. The total alpha and proton enssion cross sections compared to the portion of the inelastic neutron cross section that results in photion emission.

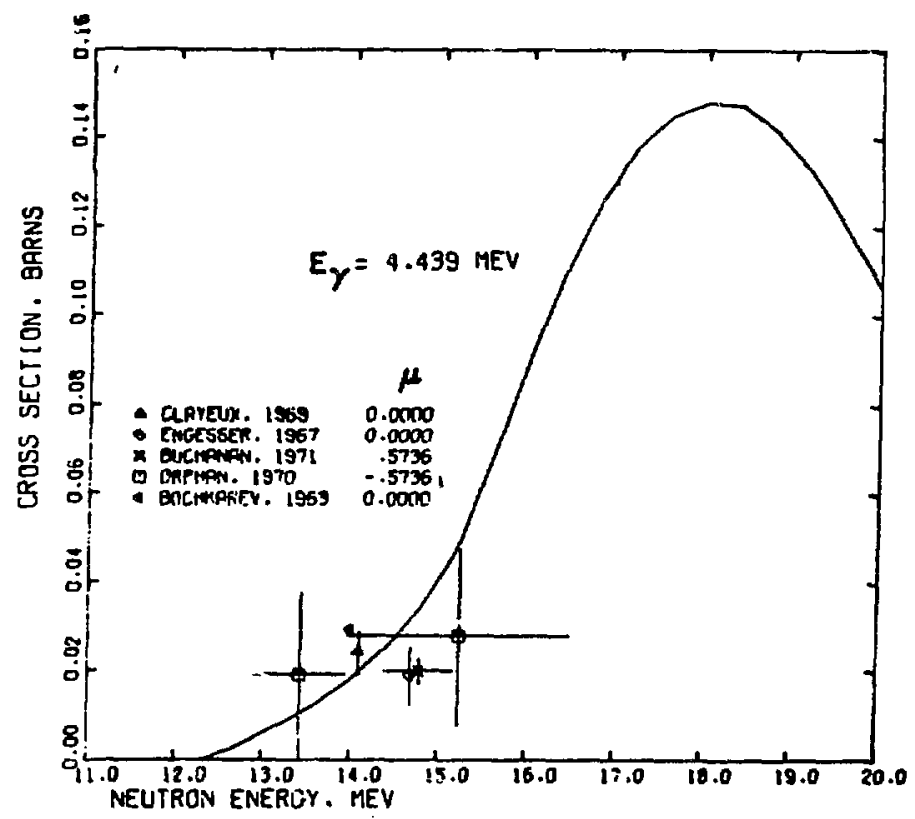

Fig. 32. Measured and evaluated $\left(n, n^{\prime} \alpha y\right)$ cross section for the 4.439-MeV phoxion. 
A significant portion of the $\left(n, n^{\prime} \alpha\right)$ cross section results in excitation of the first excited level at $4.439 \mathrm{MeV}$ in ${ }^{12} \mathrm{C}$, with subsequent emission of a photon of that energy. We made a crude estimate of the $\left(n, n^{\prime} \alpha \gamma\right)$ cross section from the $\left(n, n^{\prime} \alpha\right)$ data using a technique described earlier (Yo72), and the results are compared to the available photon-production measurements in Fig. 32. The threshold for photon production following $(n, n$ 'p) reactions does not occur until $18.49 \mathrm{MeV}$, and we have ignored photons from this reaction in this study.

\subsection{Elastic Scattering Cross Section}

Although the threshold for the $(n, \alpha)$ reaction is $2.35 \mathrm{MeV}$, this channel does not become important until nearly $4 \mathrm{MeV}$, and at lower energies the elastic cross section is essentially equel to the total cross section. The elastic cross section obtained from our analysis of the total is compared in Fig. 33 to the available elastic measurements between 0 and
$2.8 \mathrm{MeV}$. Similarly, Fig. 34 includes the elastic results between 2.8 and $6.0 \mathrm{MeV}$. Above $4 \mathrm{MeV}$, the $(n, \alpha)$ cross section has been subtracted from the total to give the elastic curre. Clearly, the elastic meesurements shown in Figs. 33 and 34 are in reasonable agreement with the evaluated curve, although the measurements do not show much of the structure displayed by the total cross section. Below $6 \mathrm{MeV}$, the Slaggie and Reynolds (S165) elastic data are only slightly different from the present results, and the only important difference occurs in the window near $2.35 \mathrm{MeV}$, as noted in Sec. 2.1.

The elastic cross section from 6 to $20 \mathrm{MeV}$ is given in Fig. 35. The KAPL elastic ( 3165 ) is included for comparison. Most of the experimental points In Fig. 35 were obtained by fitting the measured angular distributions with lagendre expansions. The fitted curves above $7 \mathrm{MeV}$ were anchored at front and back angles by inserting into the fit fictitious

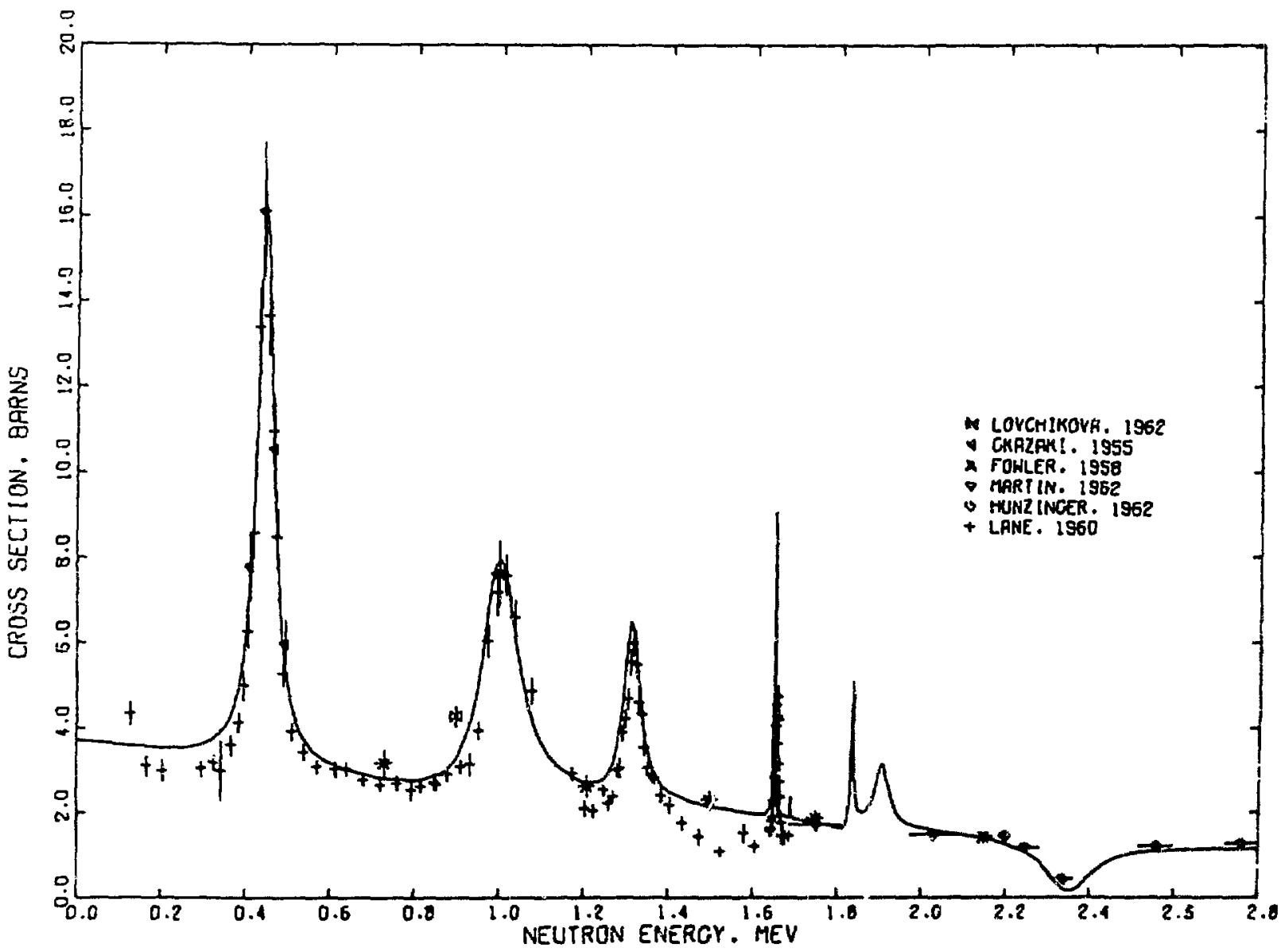

Fig. 33. Measured and evaluated elastic scattering cross section for 0 rron 0 to 2.8 MeV. 
points at $0^{\circ}$ based on 'N1ck's 1 im1t (W143) and points at back angles based on optical model calculations.

The evaluated curve below $11 \mathrm{MeV}$ was obtalned by subtracting the sum of all reaction cross sections from the total cross section. Between 11 and $14 \mathrm{MeV}$ the emphesis was shil'ted to the elastic measurements, and near $14 \mathrm{MeV}$ the elastic was obtained directly from experimental data. To extend the elastic cross section to higher energies, the parameters of a spherical optical model were fitted to the angular distribution measurements near $14 \mathrm{MeV}$. The depth of the real potential was then varled to reproduce the total cross section to $20 \mathrm{MeV}$, and the elastic cross section was obtained by subtracting from the fluctuating total cross section a smooth nonelastic cross section based on the calculations.

The evaluated elastic cross section is in good agreement with most of the measidements in Fig. 35, although the curve is somewhat higher than the measurements near 11 and $11.6 \mathrm{MeV}$, Above $9 \mathrm{MeV}$, the evaluated curve is substantially higher than the KAPL results (S165). The 1953 cloud chamber measurement by Conner ( $\cos 3$ ), which rovshly agrees with the KiPL data, was not emphasized in the present study.

\section{ANGULAR DISTRIBUTIONS}

3.1. Elast1c Neutron Angular Distributions

The evaluated angular distributions for elastic scattering by Slaggle and Reynolds (S165) yere adopted for neutron energles below $5 \mathrm{MeV}$. Fron 5 to $14 \mathrm{MeV}$ smooth curvee were drawn through the coeffs.clents obtained from Legendre rits to the ovallable experimental data. Above $7 \mathrm{MeV}$ the fits were anchored at front and back angles using w1ck's limit (w143) and optical model calculations, as noted earlier. Above $14 \mathrm{MeV}$ the behavior of the legendre coefsiclents was estimated from the optical mollel calculat.ions that were used to extrapolate the elastic cross section to $20 \mathrm{MeV}$ (Sec. 2.7).

In Fig. 36 the evalusted legendre soeffictents* for $l=1$ through $l=4$ are compared to the fitted values for neutron energies above $5 \mathrm{MeV}$. Similarly, the cuefficients for $l=5$ through $l=10$ are given In Fig. 37. Near 11 MeV there are significant differences in the $l=7$ and $l=8$ coefflelents from

\footnotetext{
These coefficients are in the BNDF form defined

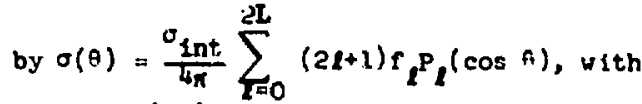
$s_{0}+1$ and $\left|f_{l}\right| s i$.
}

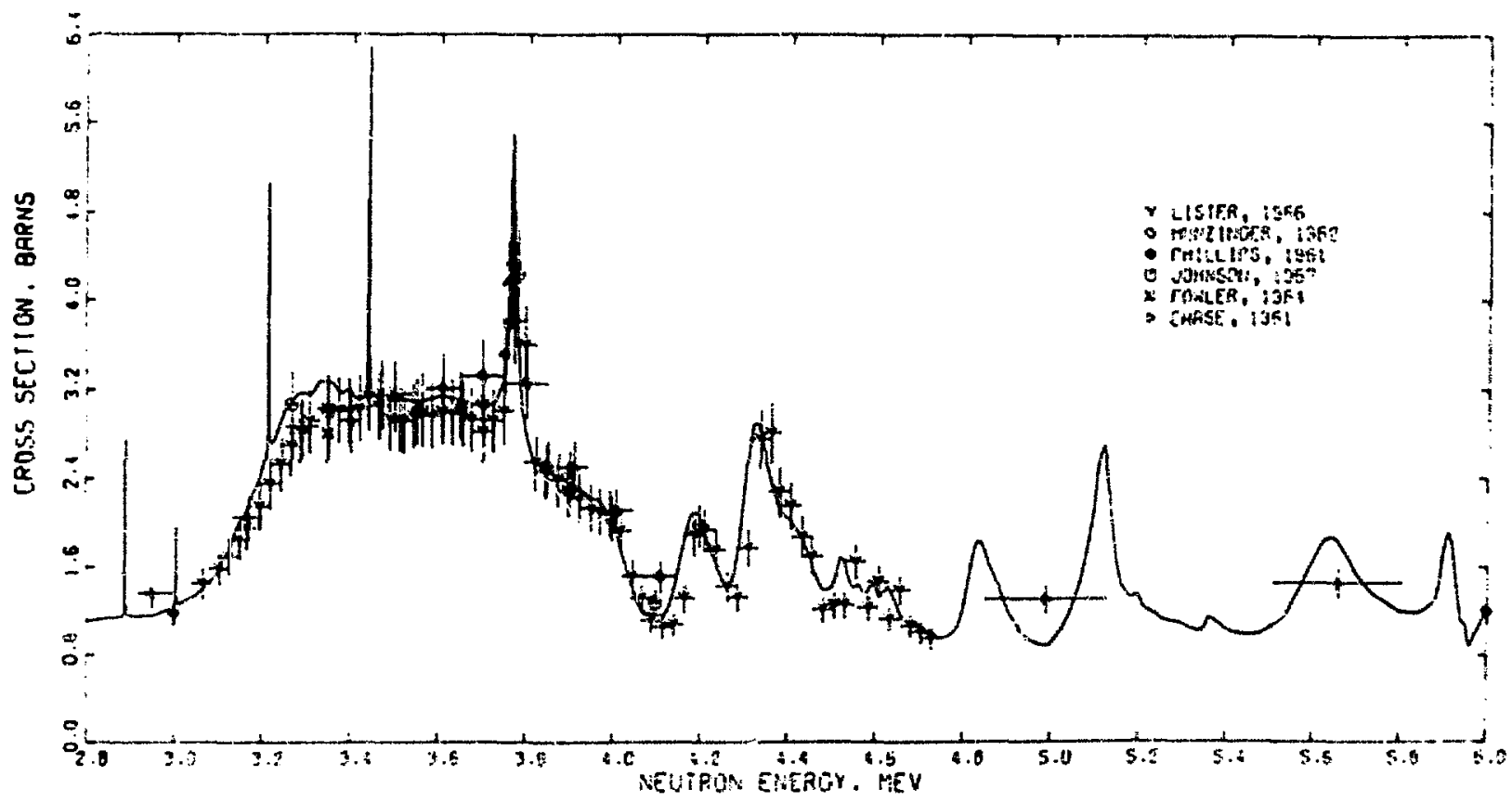

Fig. 34. Measured and evaluated elastic seattering cross aection for ${ }^{16} 0$ from 2.8 to $6.0 \mathrm{MeV}$. 


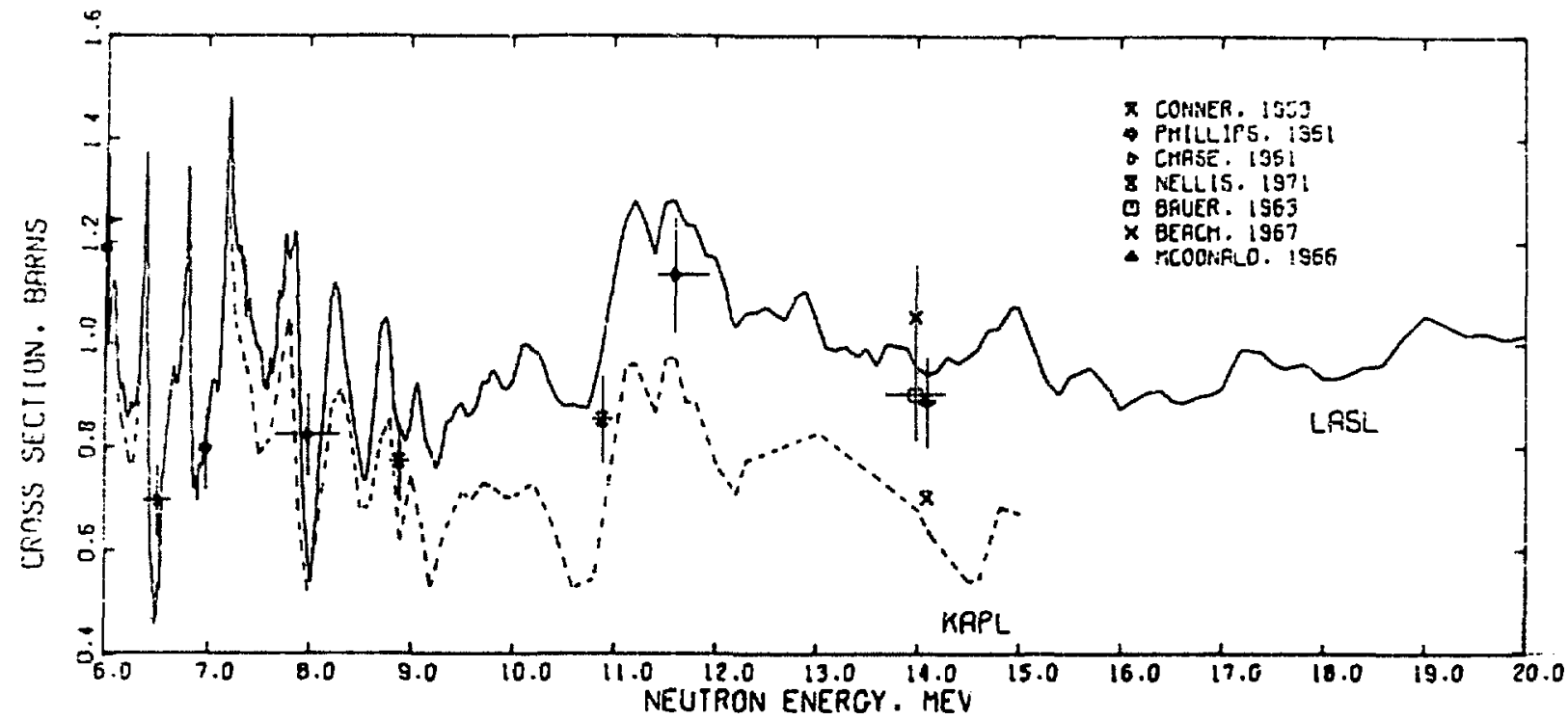

Fis. 35. Messured and evaluated elastic scattering cross section for 160 from 6 to $20 \mathrm{MeV}$.

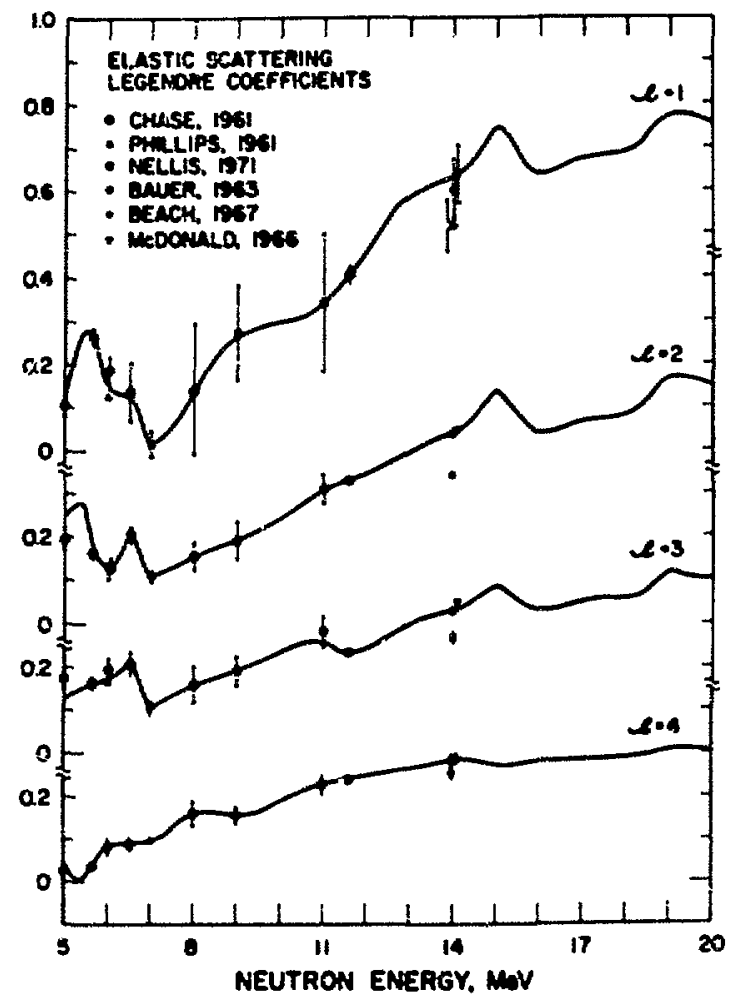

I5. 36. Messured and evalusted Legendre coerf1clents for $l=1$ through $l=4$ at neutron energies above $5 \mathrm{MeV}$. The ERDF/ convention is used for the coefricients $\left(r_{0}{ }_{1}\right)$.

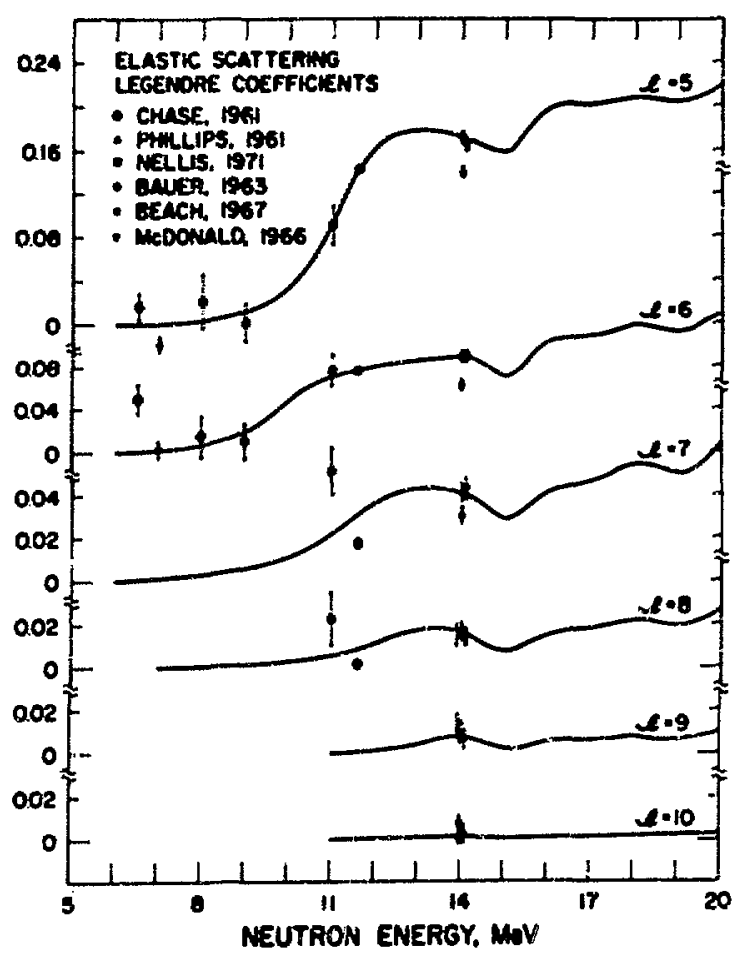

F1g. 37. Messured and evaluated Legendre coefficients for $l=5$ through $l=10$ at neutron energies above $5 \mathrm{MeV}$. 
the Mellis et al. (Ne71) and the Chase et al. (Ch61) measurements. Thile these differences tray se real because there is structure in the total cross section near $11 \mathrm{MeV}$, we used average values for the coefficients in this analysis. Significant differences also occur in the coefficients from the Beach (Be67) data as compared to those from the Bauer et al. (Báb3) and McDonald et al. (Mc66a) measurements near $14 \mathrm{MeV}$. The results from the latter experiments were used in this anolysis.

The elastic anguler distributions are compared in Fig. 38 to the measurements between 4.99 and $6.53 \mathrm{MeV}$. Sinilar comparisons are given in Figs. 39 and 40 for the elastic measurements between 7 and $14.1 \mathrm{MeV}$. The values used in the figures for wick 's Iinit were averaged roughly over the energy resolution of the experimental measurements. The differences noted earller between the Nellis (Ne71) and Chsse (Ch61) measurements near $11 \mathrm{KeV}$ are apparent in F18. 39. Sinllarly, in Fig. 40 the evalunted curve at $14.1 \mathrm{MeV}$ differs significently from the Beach (Be67) measurement.

Angular distributions obtained from the optical model calculations are Biven in Fig. 41 for neutron energies of 16,18 , and $20 \mathrm{MeV}$. The distributions become progressively more forvard-peaked as the neutron energy increases.

\subsection{Inelastic Neutron Angulai Distributions} Neasureme of inelastic neutron angular distributions for some of the los-lying levels of ${ }^{16} 0$ have been made at 9 and $11 \mathrm{MeV}$ by Nellis et al. (Ne71) and near $14 \mathrm{MeV}$ by Bauer et al. (Baó3) and McDonald et al. (McŚ́a). The Nellis data indicate that the sum of the angular distributions to the 6.05-and 6.13-MeV levels is somewhat forward-peaked at 9 and $11 \mathrm{MeV}$, and simflar effects are observed in the measurements near $14 \mathrm{MeV}$ (Be63, Mc66a). The sum of the angular distributions to the 6.92- and 7.12$\mathrm{MeV}$ levels is nearly isotropic at $11 \mathrm{MeV}$ (Ne71),
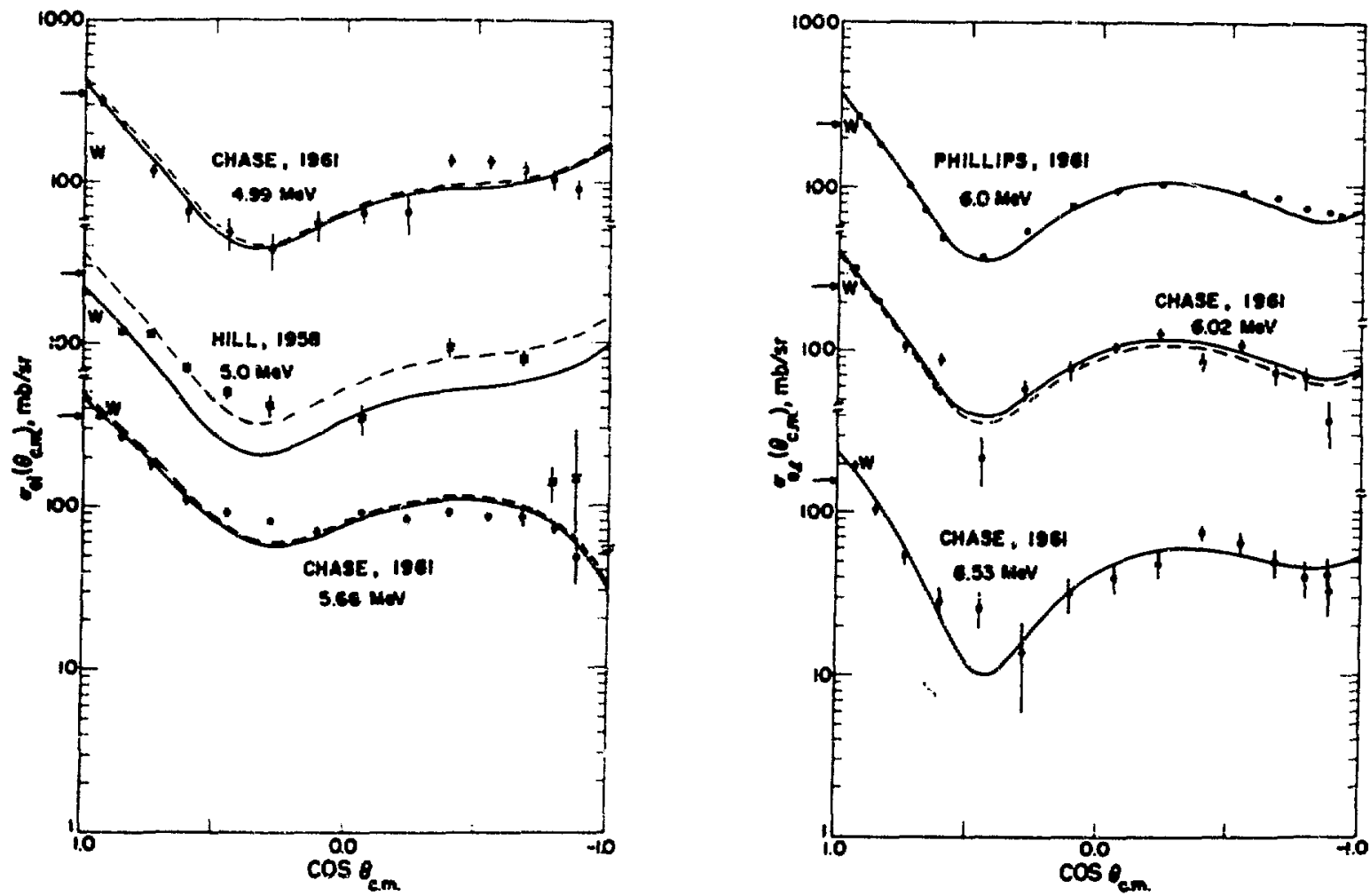

Fig. 38. Masured and evalunted angular distributions for elastic scattering between 4.99 and 6.53 Mev. The solid cirves represent the evalunted shapes normalized to the measurements; the aashed curves give the same shopes nomalized to the evalunted elastic cross sections. Wick's ifmit is indicated by the arross at the left margin. 

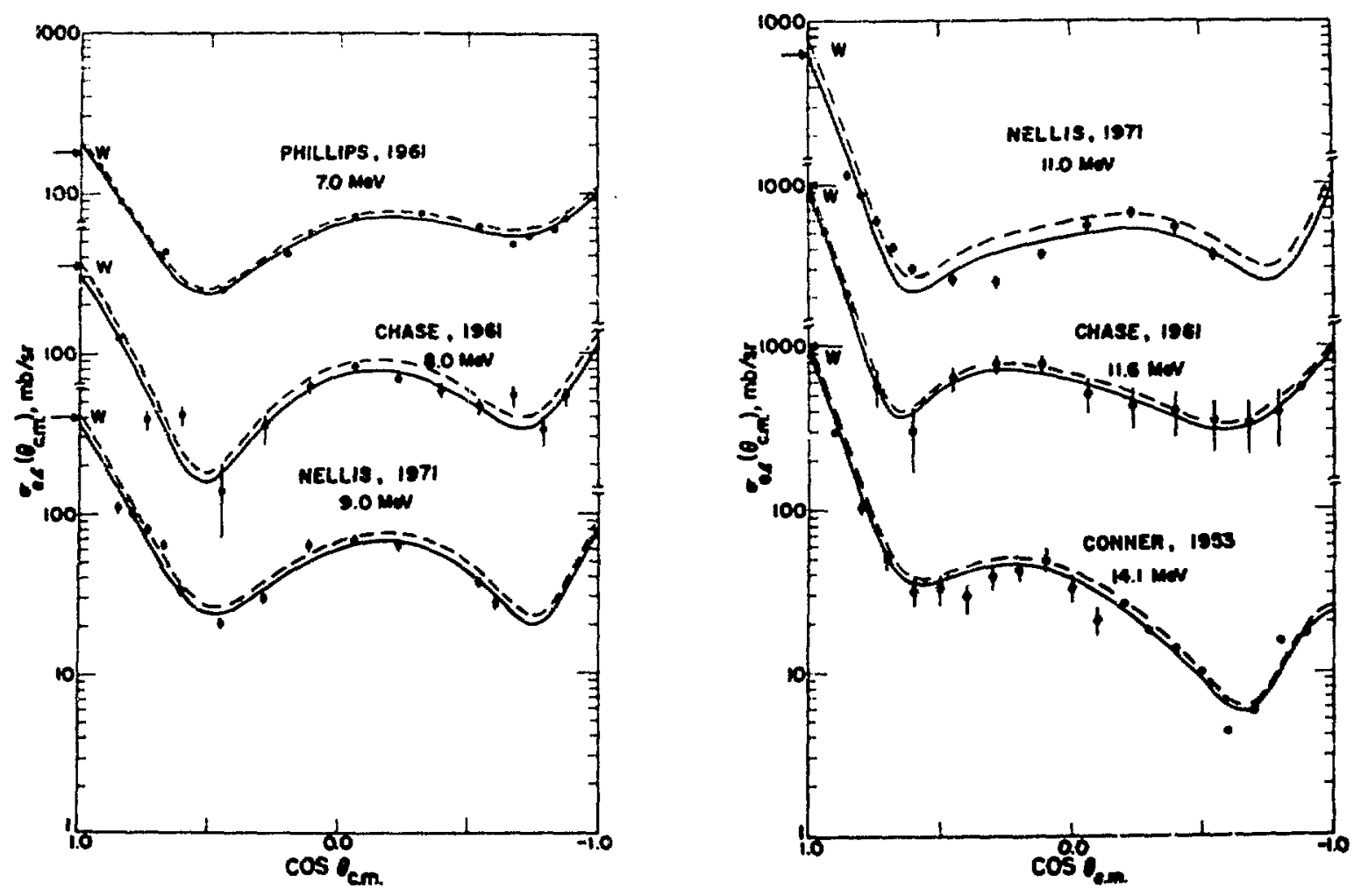

F1g. 39. Measured and evaluated angular distributions for elastic scattering between 7.0 and 14.1 MeV. See caption to Fig. 38 for details.

although slight forwand-peaking is seen in the 14-HeV measurinents (Ba63, Mc66a).

A complete analysis or the $\left(n, n^{\prime}\right)$ angular dis. tributions shouid include the results described above, together with all avatlable ${ }^{16} c\left(p, p^{\prime}\right)$ angular distribution data. We did not make such an analysis for this evalustion, and the inelastic neutron angular distributions are assumed to be isotropic throughout. These results are regarded as prelimInary, and Improvements are planned for the ruture. 3.3. Secondary-Photon Angular Distributions

The angular distributions of all photons yere assumed 1sotropic in the evaluation. This assumption is known to be Invalid for the 6.13-MeV photon at $7.5 \mathrm{MeV}$, where the measurement of Drake et al. (Dr70) indicates pronounced forward-peaking, with $o\left(0^{\circ}\right) / \sigma\left(90^{\circ}\right)$ being roughly equal to 2.2. Similarly, near $14 \mathrm{MeV}$ the results of Kozlouskl et al. (K065) and Buchanan et al. (Bu71) establish $\sigma\left(0^{\circ}\right) / \sigma\left(90^{\circ}\right)$ to be approximately 1.5. Since the 6.13-MeV photon is very important in the million-electron-volt neutron energy resion and since knowlodge of the angular distribution is needed to evaluate the integrated cross section sroperly, the result given in this evalustion are regarded as tentative, and future sork including theoretical considerations is planned.

The results of Morgan et al. (Mo64) indicate that the assurption of isotropy is reasonably valid at $14.8 \mathrm{MeV}$ for the $2.74 \mathrm{~m}, 3.09-, 3.68-$, 3.85-, $4.44_{-}, 6.92-$, and 7.12-MeV photons.

\section{DIscussiar}

He have mentioned several areas where the present evaluation is deficient and iaprovements are needed. The most important of these are the 6.13MeV photon angular digtrlbutions, whick also affect the $\left(n, n^{\prime}\right)$ and $\left(n, n^{\prime},\right)$ cross sections inferred from

\footnotetext{
"The data of Morgan et al. (Mo54) are superseded by the results of Burhanan et al. (Bu7I): the latter reference, hosever, contains explicit dnte only on the angular aistribution of the 6.15 -MeV photon.
} 

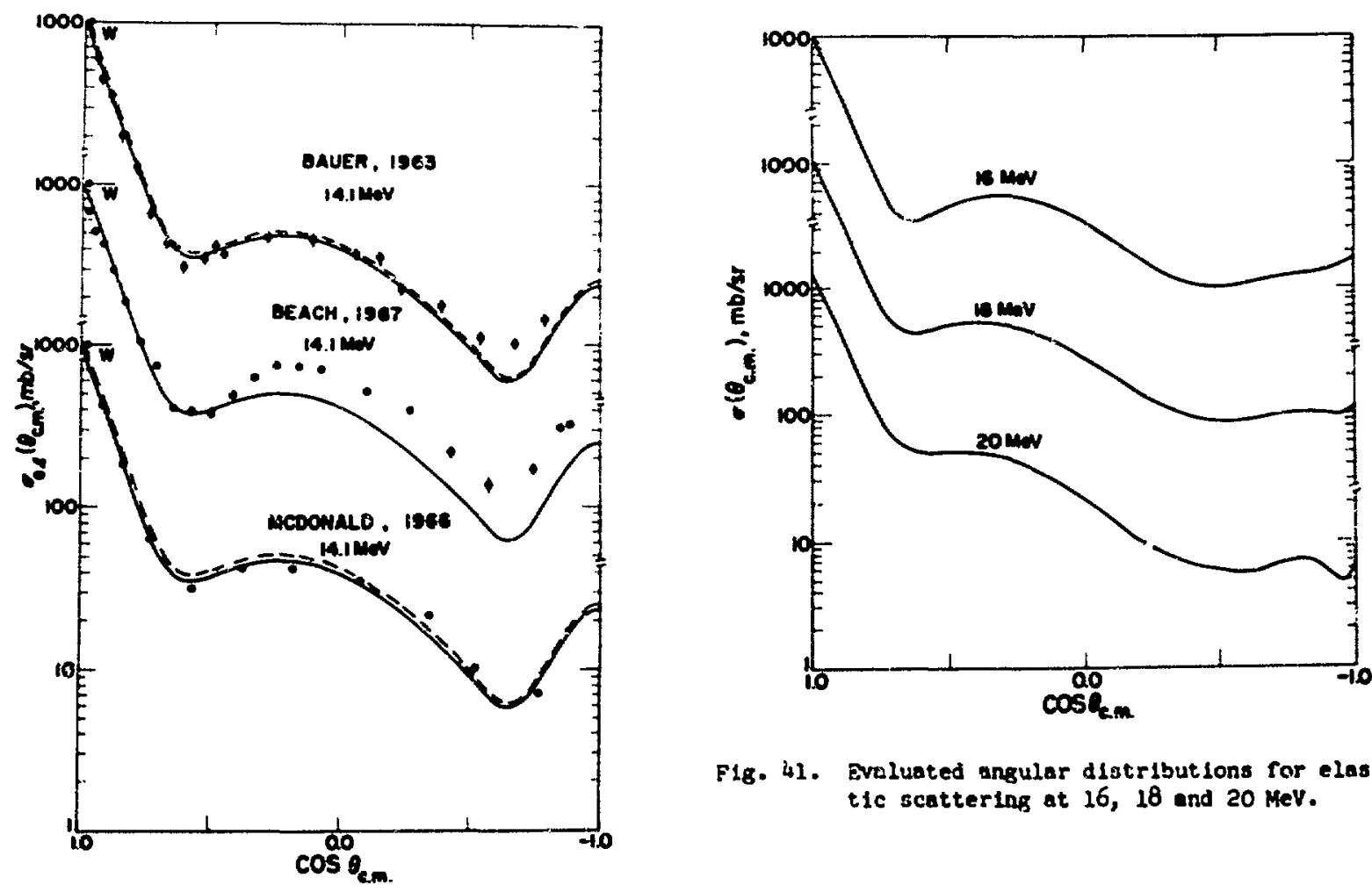

Fig. 41. Evoluated angular distributions for elastic scattering at 16,18 and $20 \mathrm{MeV}$.

F-8. 40. Heasured and evaluated angular distrlbutlons for elastic scattering at $14.1 \mathrm{MeV}$. Ste caption to $\mathrm{Fig}$. 38 for detalls.

2002 ข

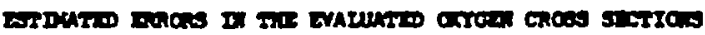

\begin{tabular}{|c|c|c|c|c|c|c|c|c|c|c|}
\hline \multirow{3}{*}{$\frac{\text { Crone secesoe }}{\text { rotel }}$} & \multirow{2}{*}{ 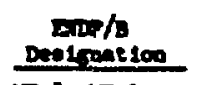 } & \multirow{3}{*}{$\frac{\operatorname{mena1}}{ \pm 4 x}$} & \multirow[b]{2}{*}{$0.2 \mathrm{nev}$} & \multirow[b]{2}{*}{$2 \mathrm{nur}$} & & \multirow[b]{2}{*}{$\underline{21 \mathrm{mer}}$} & \multirow[b]{2}{*}{$16 \mathrm{Nar}$} & \multirow[b]{2}{*}{$20 \mathrm{mr}$} \\
\hline & & & & & $3 \mathrm{max}$ & 3006 & ont & & & \\
\hline & $n a-3, \quad x a=1$ & & $\pm b s$ & \pm 13 & \pm 26 & \pm 15 & \pm 28 & \pm 25 & \pm 28 & \pm 25 \\
\hline Elent Is" & seres, $x T^{2}=2$ & 4 & $\$$ & 15 & 15 & 36 & 68 & 23\% & $20 \%$ & 206 \\
\hline Monelautic & $=0-3,10-3$ & 245 & $\begin{array}{l}\text { order } \\
\text { of mat- } \\
\text { aleute }\end{array}$ & $\begin{array}{l}\text { order } \\
\text { of mate- } \\
\text { altude }\end{array}$ & 205 & 20.6 & 258 & 306 & 206 & 505 \\
\hline rotenl $(n, \infty)$ & wos, nerest & - & - & - & - & - & 306 & 306 & 306 & 306 \\
\hline $\begin{array}{l}\text { Diecreete }\left(n, D^{0}\right) \\
E_{x}\left(2 E_{0}\right)<13 \mathrm{~min}\end{array}$ & $\begin{array}{l}n=3 \\
n=51\end{array}$ & - & - & - & - & - & 305 & 30.5 & 30 & 30 \\
\hline $\begin{array}{l}\text { Diserete }\left(n, n^{\prime}\right) \\
E_{x}\left(16_{0}\right)>13 \text { yev }\end{array}$ & $\begin{array}{l}M T=3 \\
M T=71\end{array}-89$ & - & - & - & - & - & - & - & - & sos \\
\hline$(n, 7)$ & $\begin{array}{l}\text { RT=3 } \\
\text { MT=10R }\end{array}$ & 165 & $\begin{array}{l}\text { lover } \\
\text { linit } \\
\text { oaly }\end{array}$ & & & & & & & \\
\hline$(n, p)$ & $n=-3, n-20]$ & - & - & - & - & - & - & 206 & 24 & 206 \\
\hline$(n, d)$ & $M T-3, \mathrm{MT}=10 \mathrm{~K}$ & - & - & - & - & - & - & sos & 306 & sos \\
\hline$(n, \infty)$ & nemes, ver=107 & - & - & - & 20 & $20 \%$ & 20 & $2 \alpha$ & 265 & $20 \%$ \\
\hline Totel $(x, x y)$ & 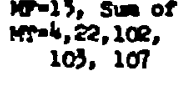 & - & : & - & - & - & 306 & 30 & 3010 & 30.5 \\
\hline $\begin{array}{l}\text { Individuol } \\
(0, x y) \text { 110ee }\end{array}$ & 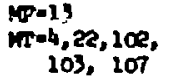 & $=$ & - & - & - & - & $30 \%$ & 36 & $3 \alpha$ & $30 \%$ \\
\hline
\end{tabular}

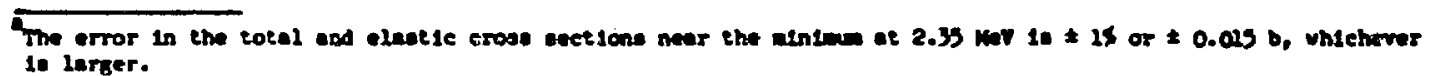


the photon measuretients. Aress involving the inelastic neutron angular distributions and the elastic scattering ansular distributions belos $-6 \mathrm{MeV}$ also need 1mproving. The KAPL evaluat 1on (S1ós) was used for the latter belou $6 \mathrm{MeV}$, and a detn1led resonance-theory analys is incorporating pore recent measurezents *ould laprove the data set. Finally, more careful reacilon-theory calculations should lead to Lmprovements in the Inelastic neutron cross sections at righer energies.

A sumary of the estimeted uncertaintles in the varlous c.oss sections is eiven in Tublo $V$ at several representative neution eneristes. The estimeses are rough and are not expected to hold true in detall. In addition, the errors are averaged over the structure in the cross sections, and allowance for uniknown structure is not included. Tise-or-r2ight spectre of neutrons emerging from llquild oxygen upheres pulsed by 14 theV neutrons have been calculated by Harris et al. (Ka71) using the present date set and compared

\section{ABPREICES}

Ad49 R. K. Ada1r, H. H. Barschall, C. K. Bockelman, ead O. Sale, Total Cross section of Be, $O$, Ma, and Ce for Fase Reutrons," Phys. Rev. 75, $1124(1949)$.

Aj59 F. A. Ajzenbers-Selove, and T. Lauritzen, "Dneroy tevels of Liont thelei VI, Hacl. Phys. 11,1 (1959).

Aj70 F. Ajzenbers-Selove, "Dnergy Levels or Light ruclel A=13-15," Tuel. Prys. A152, 1 (2970).

AJ71 F. Ajrenberg-Selove, "Bnergy Levels of Lighe nucled $A=16-17$," Iucl. Fhys. Al65, 1 (1971).

Ba63 9. H. Bauer, J. D. Anderson, end L. J. Christensen, "Scattering of $14 \mathrm{HeV}$ Meutrons Prom kitrogen and oxyken," Mucl. Phys. 4?, 242 $(1963)$.

gé67 P. L. Gench, R. ri. Finlay, R. L. Cassola, and R. D. Koshel, "Elnstic scateering of seturons Prom $O$ and As to $\$ 4.0 \mathrm{MeV}$, "Phys. Rev. 156 $1201(1 \% 67)$.

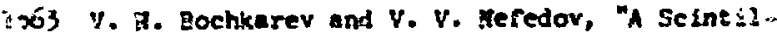
lneton $r$-Ray spectrotet $u 1 t$. Fast Neutron Diserinination," Pribory i Tek. Exs. 3, 1016 (1955).

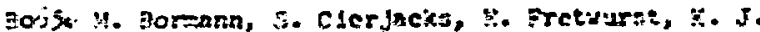
iefects, :3. Siterert, and H. Pollehn, Thter* whungen ijber die Bnergleabhäniskete ron *: nreakefonch ait ifeutronea fa Brergiebeir: th zutzchen 12 und $19 \mathrm{MeV}, "$ ?. Phys lk 174, (. 9051 . to the experifental measurements of Kansen $\mathrm{ct} a \mathrm{~J}$. (Ha70). The calculations, ade uth the mulitgroup 'lonte Cnrlo code ArDY, afree reasonably vell y ith the measuresents, considerins the uncertainties associated with the salculation and the cross-section errors given in Table $v$.

\section{ACTOROTLEDRARTSS}

He rish to thank $C$. L. Dunfond for performing the corenc calculations used in this sork and $T$. A. pitterle for conalderabla assiatance in evaluating the $(n, p)$ und $(n, a)$ cross sections. We also wish to thank L. Stevart for many useful comente, and are very graterul to D. H. Mcclelien, C. I. gaxian, and $\mathrm{x}$. Haines for their help with the cleriest tasks needed for this atuly. "Inelly, ve graterwly acknouledge the contributions of the many authors tho provided us vith their experimental resulcs in advence or publication.

B067 4. Bormann, F. Dreyer, H. Newert, I. Rlehle, and $v$. 7.1el1usk1, "Cross-sections of sooe $(n, p),(n, t)$, and $(n, \alpha)$ zeact ions in the rittrogen Dherb Pegion 13-19 4 ev," Conference on Nucleer Date, perls, (Internne Iond htomic Drergy Agency, YLenn, 1967) (1960), 0. Z2j.

3ril 0. D. Bril2, H. A. Vlasov, 5. D. Rollinen, and l. S. Sotsitiov "Crops tigction of the $(n, 2 n)$

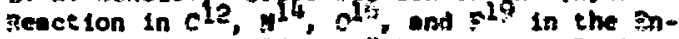

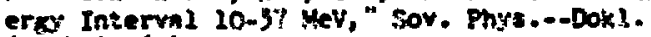
6. $24(1901)$.

Bu? 1 P. 5. Buchanan, D. O. Mell1s, and it. E. Tucker, "A Complletion of cross sections a.d ansular Distribution: of Gamen pays Produced by Feutron Bowberdient of Yarlot Muclet, " Fuclenr-

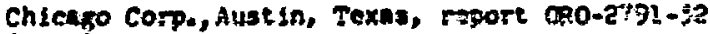
(1971).

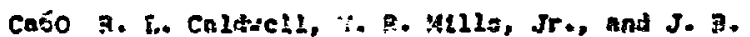

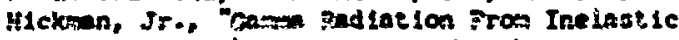
Scatering of 14 -tideV reutrons by the comon Surth Elements," Much. 3es. Ses. 6, 173 (1360).

Ch61 I. F. Chrse, Jr., R. Y. Juth, ㄱ. G. Johnson, F. J. Vaughn, and 4 . sele, pres Meutron cross Fections of exygen and Mitrogen," Air Fore?

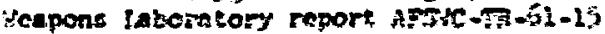
(1551).

Cséb S. Clerfacks, P. Port1, D. kopsch, t, propp, J. Hebe, and 11. unseld, High aerolition josl Cross sections betueen 0.5 - $30 \mathrm{HeV}$ " Kenforschumszentre report ax-1000 (17ts). 
Ci71 5. Cierjacks, private cominicaision (19?1).

C169 G. Clayeur and G. Grenler, "Speetres de renyal des gaw prafults par des neutrons de If.1 Sev" "Comisserlat a l'inerg le Atonlque report cos - ? $-580 ?$ ? (1959).

Co53 J. ?. Conner, "A Cloud-shamber study of the Senttering of sast ieutrons in Cxysen," Phys. Rev. 69, $7: 2$ (1953).

Da6j E. A. Davis, T. \%. Bonner, D. H. forley, Jr., and s. Bass, "Dfsintegration of 016 and $c^{12}$ by Tast Heutrons," Nucl. Phym. 48,169 (1963).

Dá68 D. Dandy, J. L. Wanisling, and c. J. Pernell, "The Crose section for the $130(a, a) 13 \mathrm{C}$ Resc-

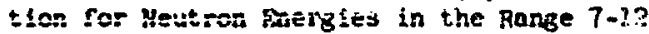
UfV," Atomis Hewpons Research Establishment report AirRe $0.60 / 68(1968)$.

De.6o J. A. DeJiwen gnd R. if, Stooksberry, Measurezent of the $0^{10}(n, p) n^{16}$ Cross section at 24.7 Mev," Phys. Rev. 120, 901 (1.960).

De62 J. A. DeJuren, R. H. Stookgberry, and $M$. Nal113, "Heasurement of the $0^{26}(n, p) n^{16}$ Cross Sect lon rrom 11 to 19 Mev," Phys. Rev. 127, 1229 (1902).

DI67 A. S. Divat ie, K. K. Sekhoran, and H. K. Mehta, ${ }^{10} 0(n, \alpha) 13 c$ Reaction Cross-Sectiona from the $13 c(\alpha, n) 150$ React ton," Conference on Nuclaer Data, Peris, (Internntional Atomle thr eres Agency, VIensa, 1957), p. 233.

$0: 70$ J. K. Dickens and 5. G. Perey, "The $160(n, x)$ Reaction $\operatorname{tar} 6.7 \leq E_{n} \leq 12 \mathrm{MeV}$, "Hucl. Sel. Dis. 40, $283(1970)$.

Dr70 D. M. Drake, J. C. Hopkins, and C. S. Youns, "Cans-Ray-Production Cross Sections for Fist Restron Interact ions yth several slements," Nuel. Sc1. Sng. 40, 694 (29\%0).

DuTl C. L. Dunfont, private comanication (1971); see lso C. "L. Dunford, "A Untfied Fodel for Anulyals of thupound Vucleus Reactions," Atoalcs Inteitationd report $A I-A X-12931$ (1970).

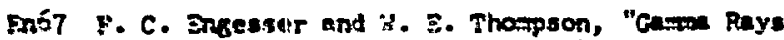
flesulting frcm Interactsens of $14.7 \mathrm{HeV}$ Hevtrons sith Varlous Elements," J. Nucl. Derso 22, 1487 (2967).

Fo58 J. L. Fouler and H. O. Cohn, "axygen Differential Meutron Scntterinz and Phenonenologicel Fucleer Potentinls, " Phys. Rer. 109, 69 (2986).

Fóil D. 3. Fossnn, 7. 2. Bnlter, 3. F. Yilson, and 4. H. Inrechn!2, "trutron Totul Cross Sect tons of $\mathrm{Be}, \mathrm{g} 20,3, \mathrm{C}$, and $0, \cdots$ Phys. Pev. 203,209 (1961); see ailso $\mathrm{J}$. C. Davis and F. T. Kode, Teutron Bnerify Deterfinat iens," Fucl. Phys. 1134, 361 (1919).

Fót J. L. Forler ant C. H. Jothion, Foe Scotter-

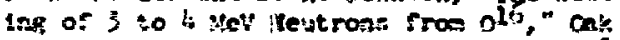

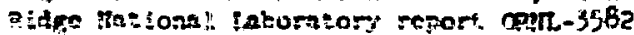
$(2904), 50$.
Fo70 J. L. Forsler and C. H. Johnson, "D1fferential Scattering of Neutrons at Narrow Levels in 170 ," Phys. Rev. C2, 124 (1970).

So71 D. G. Foster, Jr., and D. H. Glasgow, "Neutron Total Cross Sections, 2.5-15 MeV. I. Exper 1mental," Phys. Rev. C3, 576 (1971).

Fo?la J. L. Fouler, C. H. Johnson, F. X. Haes, and P. M. Frescel, "The Neutron Total Cross Sec$t$ ton of 160 and 40 ca," aak Ridge nstional Iabo:tetory report Caif-710301 (1971), p. 179.

Ha59 H. E. Hall and T. H. Bonner, "Game Radlactions from Inelast 1c Scattering of Fast Neutrons in c12, 14 , and $0^{16}$, Nucl. Phys. 14, 295 (1959).

Ha70 L. F. Itansen, I. D. Anderson, E. Coldberg, J. Kanserdiener, E. Plechaty, and C. 师g, "Predletions for Neutron Transport in $A 1 r$, Based on Integral Mensurements in Mitrogen and oxygen at it MeV," Nuel. Sct. Eng. 40, 2ije (1970); L. F. Hansen, J. D. Anderson, J. L. Kawerdiener, tind C. Johs, "Sensitivity of Monte Carlo Caj.cuiations to the Neutron Cross Sections for Neution Transport in Nitrogen and in A1r," Lawrence Livermore Laborato:y report UCRL-51031 (1971).

Ha 71 D. R. Harr 1s, D. R. Koen18, and N. Preog, Thuleigroup Montie Carlo and $S_{n}$ Mechods for Mir Trensport," Seminay on Rediat ion Transyort in Air, Novemeer, 1971, Radiation Shiclding InFormetion Center, oak Ridge, Tent. (oukASIC-33) p. 209.

H158 R. $A$. HIII, "Angular Distribut lons of Elust ic Seattering of 5 - Mel Neutrons," Phys. Rev. $103,2105(2988)$.

He67 Y.-C. Heu, C.-Y. Huang, and C. -C. Chars, "Angular Distributions of Alpha particles from the Reaction $16 \mathrm{O}(\mathrm{na}) 23 \mathrm{C}$ at $\mathrm{g}=14.1$. MeV, "Nucl. Phys. 1204, 67? (2967).

Húb2 4 . Hunz inger and P. Huber, "oltferentieller N1rkungsquerschnite von Seuerstof $f-16$ für Heutroaen in Hev-Inerg,leber(tich," Hely. Phys. Acti 35, 351 (1962).

Jo48 H. B. Jones, Jr., "Slow Meutron Cross Section of $\mathrm{H}, "$ "Phys. Rev. 74, 364 1,2948:"

J067 C. H. Johnson and J. L. Fouler, "Scattering of Heutrone from $26_{0}$ in the 2.2 - to 4.2 HeV Inercy pange," Phys . Rev. 162, 890 (1967).

$5 u 63$ E. T. Jumey and H. T. Motri, Mhermal Reutron Capture in 0 and 016 ," Argene rational Laboratory report AllL-6?9? (1503), p. 235 .

Ju71 E. T. Jumey, privete comunication (1971).

Kás? J. Kantele and D. C. Cardner, "Some nctivation Cross sections for 14.7 MeV Reutrons," Nucl. Phys. 35, 353 (2962). 
Ka71 J. Kalyna, I. J. Teylor, end L. J. Lidofsky, "Total Neutron Cross Section of 160 at 2.37 Mev," submitted to Third Conference on Neutron Cross Sections and Technology, Knoxsville (1971), Abstract No. IT.26; and private comnunications (1971).

K065 T. Kozlowski, N. Kusch, and J. Wojtkowska, "Gamna Rays from Inelastic Scattering of 14.1 Mev Neutrons on $c^{12}$ and 016 , "Polish Acedemy of Sciences report $\mathrm{TNR}-661 / \mathrm{IA} / \mathrm{PL}$ (1965).

La60 R. O. Lane, A. S. Langsdorf, Jr., J. E. Monahan, and A. J. Elwyn, "Tables of Differential Cross Sections for Scattering of Neutrons from Various Nuclei," Argonne nationel Laboratory report AnL-6172 (1960); see also Ann. Phys. (N.Y.) 12, 135 (1961).

Li52 A. B. Lillie, "The Disintegration of Oxygen and Nitrogen by 14.1-MeV Neutrons, "Phys. Rev. 8i, 716 (1952).

L166 D. Lister and A. Seyres, "Elastic Scattering of Neutrons from Caroon and Oxygen in the Energy Range 3.0 to 4.7 Mev," Phys. Rev. 143, 745 (1966).

Lo62 G. N. Lovchikova, "Scattering of Fast Neutrons on Nucle1," Scriet J. At. Energy 13, 648 (1962).

Ma54 H. C. Martin, "Cross Sections for the $0^{16}(n, p)$ $\mathrm{N}^{16}$ Reaction from 12 to $18 \mathrm{Mer}, "$ "Phys. Rev. 93. $498(1954)$.

Ma62 J. P. Martin and M. S. Zucker: "Differential. Cross Section and Polarizetion Angular Distributions for $0^{26}(n, n) 0^{26}$," Bull. Am. Phys. Soc. I, T2 (1962), Abstract v5.

Ma65 J. H. E. Mattauch, W. Thiele, and A. H. Wapstra, "1964 Atomic Mass Table," Nucl. Phys. 67, 1 (1965).

Mc66 17. McDicken and $W$. Jack, "The Reactions $20_{\mathrm{Ne}}(n, \alpha) 170$ and $16 \mathrm{O}(\mathrm{n}, \alpha)^{13} \mathrm{C}$ Us ing $14 \mathrm{MeV}$ Neutrons," Nucl. Phys. 88, 457 (1966).

Mc66a W. J. McDonald, J. M. Robson, and R. Malcolm, "Scattered Jeutrons and Ganma Rays from the $16_{0}\left(n, n^{3} p\right) 160$ Reaction at $F_{n}=14.1 \mathrm{MeV}$," Nucl. Phys. 75, 353 (1966).

Me49 E. Melkonian, "Slow Neutron Velocity Spectrometer Studies of $\mathrm{O}_{2}, \mathrm{~N}, \mathrm{~N}_{2}, \mathrm{H}_{2} \mathrm{O}$, and Seven. Hydrocarbons," Phys. Rev. 76, 1750 (1949).

Mi66 B. Mitra and A. M. Ohose, "(n,p) Cross Sections of Some Low Z Nuclei for 14.8 MeV Neutrons," Nuel. Phys. 83, 157 (1965).

Mó́l I. L. Morgan, J. B. Ashe, and D. O. Nellis, "Angular Distribution of Gamma Reys from C, $O$, and $N$ at $E_{n}=14.8 \mathrm{MeV}$, " in Nuclear Physics Division Annual Progress Regort (Texas Nuclear Corp., Austin, 1964), p. 156.
Ne7l D. O. Nell1s, P. S. Buchanan, N. C. Martin, W. E. Tucker, G. H. Williams, and A. J. Wolfram, "Neutron Scattering and Gamma-Ray Production Cross Sections for $\mathrm{N}, \mathrm{O}, \mathrm{Al}, \mathrm{Si}, \mathrm{Ca}$, and $\mathrm{Fe}$," private communication (1971).

Ny70 K. Nyberg, B. Jönsson, and I. Bergqvist, "ligh Resolution Measurements of Gemme Rays Produced by $15 \mathrm{MeV}$ Neutrons," Aktiebolaget Atomenergi report AE-INSN-2 (1970), Sect. V.

Ok55 A. Okazaki, "Scattering of Polarized Neutrons by Heary Nuclei," Phys. Rev. 99, 55 (1955).

Or70 V. J. Osphan, C. G. Hoot, and J. Joh, "GammaRay froduction Cross Sections for the $160(n, x y)$ Reaction from 6.35- to $16.52-\mathrm{MeV}$ Neutron Energy," Nucl. Sci. Eng. 42, 352 (1970).

Pa53 E. B. Paul and R. L. Clarke, "Cross-Section Mesasurenents of Reactions Induced by Neutrons of $14.5 \mathrm{MeV}$ Energy," Can. J. Phys. 31, 267 $(195 \%)$.

Ph6l D. J). Phillips, private communication to R. J. Howerton $(1961)$.

Pr66 R. Frasad, D. C. Sarkar, and C. S. Khurana, Measurement of $(n, p)$ and $(n, \alpha)$ Reaction Cross sections at 1.t.8 MeV," Nucl. Phys. 85, 476 (1966).

Sc7l R. B. Schwart,z, private communication (1971).

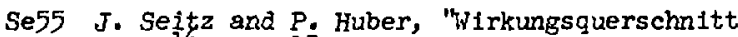
der $0^{16}\left(n,(x) c^{13}\right.$ - Reaktion fur schnelle Neutronen," Helv. Phys. Acta 28, 227 (1955).

Se62 K. W. Seemann and W. E. Moore, "The $0^{16}(n, p)$ Ni6 cross section from 12.6 to $16.3 \mathrm{MeV}$," knolls Atomlc Power Laboratory report KAPL-2214 (1962).

S168 I. Sick, E. Baumgartner, P. Huber, and Th. Stambach, "Messung des differentiellen Hirkungsquerschnitts der Reaktion ${ }^{16} \mathrm{O}(\mathrm{n}, \alpha)^{13} \mathrm{C}$ in Energiegebiet von $14.8-18.8 \mathrm{MeV}$, " Helv. Phys. Acta 41,573 (1968).

S165 E. I., Slaggie and J.T. Reynolds, "016 Fast Neutron Cross Sections and Legendre Moments below $15.0 \mathrm{MeV}, "$ Knolls Atomic Power Laboratory report KAPL-M-6452 (1965).

Wa57 R. B. Walton, J. D. Clement, and F. Boreli, "Interaction of Neutrons with Oxygen and a Study of the $\mathrm{C}^{13}(\alpha, \mathrm{n}) \mathrm{o}^{16}$ Reaction," Phys. Rev. 107, 1065 (1957).

Wi43 G. C. Wick, Att1 reale accadoItalia, Mem. classes sc1. fis., mat. e net. 13, 120: (1943); see also J. H. Coon, R. H. Devis, H. E. Felthauser, a:ad D. B. Nicodemus, "Scattering of 14.5-MeV Neutrons by Complex Nuclei," Phys. Rev. 111, 250 (1958), and L. Stewart, "Pvaluated Neutron Cross Sections for Tritium," Los Alamos Szientific Laborztory report LA-3270 (1965). 
Yo72 P. G. Yound and D. G. Foster, Jr., "An Evaluation of the Neutron and Gamm-Ray Production Cross Sections for Nitrogen," Los Alamos Scient if ic Laboratory report LA-4725 (1972).

Yo72a P. G. Young and D. G. Foster, Jr., "A PreIiminary Evaluation of the Neutron and Photon Production Cross Sections for Aluminum," Los 4 lamos Scientific Laboratory report LA -4126 (1972). 